\title{
Beyond the outer limits of nature by directed evolution
}

Patricia Molina-Espeja ${ }^{1}$, Javier Viña-Gonzalez ${ }^{1}$, Bernardo J. Gomez ${ }^{1}$, Javier Martin-Diaz ${ }^{1}$, Eva Garcia-Ruiz ${ }^{2}$ and Miguel Alcalde ${ }^{1 *}$

1 Department of Biocatalysis, Institute of Catalysis, CSIC, Cantoblanco, 28049 Madrid, Spain.

2 Department of Chemical and Biomolecular Engineering, and Institute for Genomic Biology, University of Illinois at Urbana-Champaign, 600 South Mathews Ave, Urbana, IL 61801, USA.

*Corresponding author: Miguel Alcalde, Department of Biocatalysis, Institute of Catalysis, CSIC, Cantoblanco, 28049 Madrid, Spain. malcalde@icp.csic.es. 


\section{Abstract}

For more than thirty years, biotechnology has borne witness to the power of directed evolution in designing molecules of industrial relevance. While scientists all over the world discuss the future of molecular evolution, dozens of laboratory-designed products are being released with improved characteristics in terms of turnover rates, substrate scope, catalytic promiscuity or stability. In this review we aim to present the most recent advances in this fascinating research field that are allowing us to surpass the limits of nature and apply newly gained attributes to a range of applications, from gene therapy to novel green processes. The use of directed evolution in non-natural environments, the generation of catalytic promiscuity for non-natural reactions, the insertion of unnatural amino acids into proteins or the creation of unnatural DNA, is described comprehensively, together with the potential applications in bioremediation, biomedicine and in the generation of new bionanomaterials. These successful case studies show us that the limits of directed evolution will be defined by our own imagination, and in some cases, stretching beyond that.

Keywords: Directed evolution, non-natural environments, non-natural biocatalysis, unnatural amino acids, unnatural DNA, gene therapy, bioremediation, biomedicine, bionanomaterials.

\section{Introduction}

Natural enzymes are highly efficient energetic models that can accelerate chemical reactions up to $10^{19}$ times, achieving kinetic perfection when the catalytic efficiency $\left(k_{\text {cat }} / K_{\mathrm{m}}\right)$ is close to the diffusion controlled limit $\left(\sim 10^{8}-10^{9} \mathrm{~s}^{-1} \mathrm{M}^{-1}\right)$ (Bar-Even et al., 2011). Unlike chemical catalysts that work under harsh conditions, enzymes show outstanding performance in very mild environments, close to the natural situations in which they typically act (i.e. atmospheric pressure, aqueous solution, and at room temperature). Indeed, they are considered as versatile biocatalysts with high regio-, stereo- and chemo-selectivity for tens of industrial, environmental and energy applications within the framework of the green chemistry paradigm (Alcalde et al., 2006). Despite these potential advantages, when we take enzymes out of their natural environment to use them in a defined biotechnology process, they just don't behave as we expect. Given that enzymes are fundamental to natural life, fulfilling key roles in strict metabolic pathways to guarantee cell survival and adaptation, they are simply not used to working in new artificial and often aggressive environments. Essentially, the millions of years of natural selection to which they have been put through have smoothly tuned their properties so that they perform a myriad of different reactions but generally, only for activities or in situations other than those of the synthetic applications we desire to manipulate.

Paradoxically, humankind has been using natural enzymes in a variety of processes (fermentations) for millennia, with the first recipe for beer 
attributed to the Sumerian civilization of the lower Mesopotamia around 2,000 years B.C. However, the "art of biocatalysis" remained somewhat dormant until the first true-biocatalytic process using enzymes was reported at the beginning of the XX century (Bornscheuer et al., 2012). During this period we have witnessed two consecutive biotechnological revolutions, led first by the invention of the polymerase chain reaction (PCR) in the eighties and followed by the development of directed evolution in the nineties, opening the way for protein engineers to enter a wonderland full of surprises and challenges (Lutz, 2010; Dalby, 2011). Directed evolution allows scientists to guide selective pressure, allowing RNA, proteins, metabolic pathways, genetic circuits or even whole cells to be evolved in an iterative manner in order to sculpt ad-hoc properties for purposes other to those defined by nature. Although there is still much to learn about protein folding, expression and the mechanism of action of enzymes, from its origins directed evolution has been used to mostly improve inherent enzyme features, such as activity, selectivity, substrate scope or stability for the synthesis of pharmacological intermediates and fine chemicals (Reetz, 2010; Wang et al., 2012). More interestingly, enzymes are now also being designed in vitro to employ them outside of their biological context in order to produce biofuels, commodities and building blocks (Denard et al., 2015). From a global perspective, directed evolution has pioneered the development of synthetic biology, establishing strong links between metabolic engineering and systems biology (Alcalde, 2015). As more and more methods to generate mutant libraries appear (e.g. genetic drift, circular permutation, ancestral libraries, etc), as well as techniques for adaptive evolution based on mutagenic PCR and recombination, the design of high- and ultra-high throughput screening assays alleviate experimental loads (Benner et al., 2007; Gupta and Tawfik, 2008; Yu and Lutz, 2011). Recently, the coupling of directed evolution and computational/in silico algorithms has brought us closer to reaching some of our biotechnology objectives that just a few years ago appeared to be mere pipedreams (Damborsky and Brezovsky, 2010; Verma et al., 2012; Kiss et al., 2013; Kries et al., 2013).

Apart from the aforementioned studies, excellent directed evolution reviews have been recently published, including those covering a historical perspective (Cobb et al., 2013), molecular approaches for library creation and screening (Shivange et al., 2009; Packer and Liu, 2015), a conceptual view of directed evolution (Bloom and Arnold, 2009; Romero and Arnold, 2009; Tracewell and Arnold, 2010; Tee and Wong, 2013) or the use of these methods for metabolic engineering and synthetic biology studies (Abatemarco et al, 2013; Currin et al., 2014). In this current review, we provide an exhaustive update of the most successful directed evolution experiments aimed at adapting enzymes and other molecules to non-natural needs in cutting-edge areas of biotechnology, illustrating how the real impact of directed evolution can transcend the limits imposed by nature and go far beyond. In particular, we will summarize recent studies that combine directed evolution with in silico and rational engineering, in order to render a set of molecules to be used in different biotechnological fields, addressing the adaptation of enzymes to non-natural environments, catalytic promiscuity 
for non-natural chemistry, the use of unnatural amino acids and the design of artificial DNA. In addition, we will consider the pioneering applications of directed evolution such as xenobiotic detoxification, biomedicine and bionanomaterials (Fig. 1).

\section{Non-natural environments}

Directing enzyme evolution so that they can withstand organic solvents has been the subject of research for decades. Such behavior is necessary to tackle dozens of transformations in which substrate solubility is an issue, from bioremediation to organic synthesis. Indeed, the first directed enzyme evolution experiment reported aimed to enhance catalytic activity in organic solvents. In the beginning of 90`s, subtilisin E was subjected to several rounds of error-prone PCR in order to improve its activity in the presence of high concentrations of dimethyl formamide (DMF). The activity of the mutant enzyme was 256-fold improved over the native counterpart in $60 \%(\mathrm{v} / \mathrm{v})$ DMF (Chen and Arnold, 1993). Since this historic and pioneering study, many other evolution campaigns have been undertaken to improve catalysis in organic solvents. For example, p-nitrophenyl esterases were improved by mutagenic PCR and in vivo shuffling in order to induce the same activity in $30 \%(\mathrm{v} / \mathrm{v}) \mathrm{DMF}$ as that of the native enzyme in aqueous solution (Moore and Arnold, 1996). Phospholipase A1 was also engineered by mutagenic PCR and DNA shuffling in 50\% (v/v) dimethyl sulfoxide (DMSO) (Song and Rhee 2001). There are also a few examples of the evolution of oxidoreductases, such as the $\mathrm{P}^{4} 50_{\mathrm{BM} 3}$ monooxygenase, an outstanding enzyme for organic synthesis (see below) that was evolved to improve its activity in tetrahydrofurane and DMSO. The combination of two co-solvents in the same screen gave rise to organic solvent promiscuity, allowing mutants to retain activity in other solvents with a different polarity and chemical nature (Wong et al., 2004). Following a similar strategy, a fungal laccase was engineered by iterative cycles of mutagenic PCR and DNA shuffling in yeast. After several generations in the presence of increasing ethanol and acetonitrile concentrations, the final variant harbored mutations at the surface of the protein that established new contacts, mainly through salt bridges or H-bonds. These adaptations reflected a structural reinforcement that permitted the laccase to retain its activity in the presence of organic solvents (Zumarraga et al., 2007).

More recently, ionic liquids (ILs), deep eutectic solvents (DESs) and concentrated seawater are being considered valuable alternatives to noxious organic solvents for a range of biocatalytic processes. ILs are ionic salts that are liquid at temperatures generally below $100^{\circ} \mathrm{C}$ (Welton, 1999; Hernáiz et al., 2010) and they are largely recognized as green solvents because they have zero to low volatility (lower toxicity than conventional solvents) and they are poorly or non-inflammable. DESs are a class of IL analogues with similar physical properties as ILs but that are cheaper and easier to prepare (Smith et al., 2014). Concentrated seawater has also been proposed as a possible solvent for several reactions, avoiding the use of drinkable water (Grande and de Maria, 2012). Employing these special liquids in biotransformations 
can do away with the need for damaging organic solvents, although only once their deleterious effects on enzyme activity can be overcome.

Directed evolution is a powerful weapon to circumvent this problem, as demonstrated for several enzymes. If we consider lignocellulosic biorefineries, ILs can reduce the recalcitrance of lignocellulosic biomass and hence, improve its bioavailability (Isik et al., 2014). Accordingly, several bacterial cellulases have been modified by directed evolution to work at high concentrations of ILs. For example, a cellulase (celA10 belonging to the GH5 family) that was isolated from a metagenomic source was evolved by sequence saturation mutagenesis (SeSAM) to be active in the presence of $30 \%(\mathrm{v} / \mathrm{v}) 1$ butyl-1-methyl-pyrrolidinium trifluoromethanesulfonate ([bmpl] [otf]); (Pottkamper et al., 2009). More recently, CelA2 ( $\beta-1,4$ endoglucanase) from another metagenomic library was also evolved by site-saturation mutagenesis to act in a $30 \%(\mathrm{v} / \mathrm{v})$ choline chloride:glycerol (ChCl:Gly) and concentrated seawater (Lehmann et al., 2012). Further saturation mutagenesis experiments in the presence of $\mathrm{ChCl}$ :Gly or 1-butyl-3methylimidazolium chloride $([\mathrm{BMIM}] \mathrm{Cl})$ gave rise to the $\mathrm{M} 4$ mutant (His288Phe-Ser300Arg) that was capable of "switching on" when a DES or IL are added, remaining almost inactive in traditional aqueous buffers (Lehmann et al., 2014). A promising use for this variant would be to produce an inactive cellulase in plants that could be activated on demand by the addition of salts or used to evolve mutants with improved performance on the substrate after pretreatment with IL. A thermophilic cellulase from Thermotoga maritime, Cel5A_Tma, has been evolved to function better in an IL pretreated switchgrass (ILSG), obtaining two variants by error prone PCR (N236D and H138R) that displayed as much as a 30\% increase in specific activity (Chen et al., 2013). Cellulases aside, a laccase (1cc2) from white-rot fungi Trametes versicolor expressed in yeast was submitted to two rounds of error prone PCR and screened in 15\% (v/v) 1-ethyl-3-methylimidazolium ethylsulfate ([EMIM] [EtSO 4$])$. The double M3 mutant had 4-fold improved activity, both in the IL and the buffer (Liu et al., 2013; Carter et al., 2014). Also, a formate dehydrogenase from Candida boidinii $(\mathrm{CbFDH})$ was subjected to mutagenic PCR and screened in the presence of 1,3-dimethylimidazolium dimethyl phosphate ([MMIm] $\left.\left[\mathrm{Me}_{2} \mathrm{PO}_{4}\right]\right)$, enhancing turnover rates 6-fold and the overall stability of the dimer (Carter et al., 2014). The N187S mutation at the interface between $\mathrm{CbFDH}$ monomers underlies this stabilization.

These first directed evolution experiments have aimed to adapt enzymes for better performance in the presence of specific liquids, offering the opportunity of important long-term benefits in terms of lower toxicity and contamination, higher yields, drinkable water savings and more ecofriendly procedures.

\section{Non-natural reactions}

Apart from enzymes in non-natural environments, the engineering of biocatalysts capable of catalyzing reactions that nature has not envisaged is extremely important in modern organic chemistry (Table 1). Cytochrome 
P450 monooxygenases are among the most intensely studied enzymes in biotechnology, a family of iron-heme-containing proteins that catalyze the insertion of oxygen into $\mathrm{C}-\mathrm{H}$ bonds (Anzenbacher and Anzenbacherová, 2003). The $\mathrm{P} 450$ from Bacillus megaterium ( $\left.\mathrm{P}_{450} \mathrm{BM}_{\mathrm{B}}\right)$, a soluble and selfsufficient monooxygenase with a reductase domain in the same polypeptide chain, has for years been considered as a case study of the quest for new activities through directed evolution. With the original intention of evolving it into a linear alkane hydroxylase, it was subjected to exhaustive directed evolution campaigns to convert the enzyme into an efficient propane monooxygenase (Lewis and Arnold, 2009). More recently, the same laboratory explored the synthetic ability of this promiscuous enzyme for nonnatural chemistry (Hyster and Arnold, 2015). Indeed, achieving olefin cyclopropanation via carbene transfer remains one of the biggest challenges in contemporary chemistry in order to synthesize natural intermediates and pharmaceuticals (Bartoli et al., 2014), and P450s have been engineered to achieve this goal. After initially testing a set of evolved P450s with broad

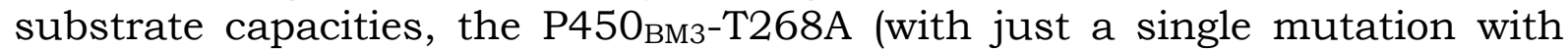
respect to wild type) was seen to be a suitable, trans-selective catalyst for the metallocarbene-mediated cyclopropanation of styrene, reporting a total turnover number (TTN) of 323. Along similar lines, the BM3-CIS-T438S variant (harboring fourteen mutations with respect to the wild type) was the highest diastereo- and enantioselective mutant (with a 92:8 cis:trans ratio and 97\% ee cis) (Coelho et al., 2013a).

The modification of key structural elements, specifically the conserved Cys residue at the heme axial ligand, significantly expanded the catalytic promiscuity of P450s (Hyster and Arnold, 2015). This activity modulation was evident by engineering a new P411 variant in which substitution of the axial ligand (Cys400Ser) shifted the Soret band from $450 \mathrm{~nm}$ to $411 \mathrm{~nm}$. This single mutation activated the enzyme's capacity to cyclopropanate styrene with ethyl diazoacetate, with a TTN of 67,800 (within whole cells), albeit at the cost of losing its natural activity for the oxidation of styrene to styrene oxide in the presence of oxygen (Heel et al., 2014). Whole cell catalysis was also possible with the P411 $1_{\mathrm{BM}} \mathrm{CIS}$ variant (with 14 mutations from wild type, including the Cys400Ser substitution), maintaining a similar efficiency while allowing the use of endogenous NADPH (mechanistically required for the reaction) instead of dithionite as a reducing agent for the heme center (Coelho et al., 2013b; Hyster and Arnold, 2015). Further mutagenesis studies have demonstrated that His at the axial position improves the catalysis of the reaction by 5 folds (Wang et al., 2014a).

The synthetic chemistry toolbox for P450s was also applied to C-N bond formation and by screening this activity within the previously mentioned $\mathrm{P}_{450}$ Вм3 monooxygenase collection, the P411 variant displayed the desired effect: oxidative $\mathrm{C}-\mathrm{H}$ amination with the use of sulfonylazides as precursors (McIntosh et al., 2013). More specifically, the P411 $1_{\mathrm{BM} 3} \mathrm{CIS}$ variant that carries the T438S substitution common to the cyclopropanation catalysts, raised the TTN from $\sim 2$ for wild type $\mathrm{P}^{4} 50_{\mathrm{BM}}$ to $\sim 400$ with $73 \%$ ee, thereby exhibiting for the first time the enzymatic introduction of nitrogen 
into an inactivated $\mathrm{C}-\mathrm{H}$ bond. A further step in this reaction is that of intermolecular amination (i.e. the formation of sulfimides), valuable building blocks mostly produced to date with organometallic systems. Once again, the $\mathrm{P} 411_{\mathrm{BM} 3} \mathrm{CIS}$ variant proved to be an active biocatalyst for the reaction after the introduction of nitrogen into thioethers, with a TTN of 300, a 30-fold improvement compared to the wild type P450

Kemp decarboxylation is a model reaction for proton transfer from a carbon atom not found in nature. A Kemp eliminase enzyme was designed in silico from a TIM barrel scaffold using quantum mechanical calculations based on the reaction mechanism (Rothlisberger et al., 2008). Since the key issue in Kemp elimination is the position of the general base for proton abstraction, the most proper surroundings to support this active site was created with the Rosetta Match algorithm (Zanghellini et al., 2006). KE07 was one of the most successful designs, involving the replacement of twenty amino acids in an imidazole-3-glycerol phosphate synthase from Thermotoga maritima. As the activity of de novo enzymes is typically weak, KE07 was subjected to seven rounds of random mutagenesis and DNA shuffling to boost the catalytic efficiency as much as 200-fold (Khersonsky et al., 2010). KE70 also appeared among the computational designs with a polarized His as the base for proton abstraction rather than the carboxylic acid side chain in KE07. In this case, a total of nine rounds of in vitro evolution combined with designed substitutions improved the Kemp elimination activity on 5nitrobenzisoxazole more than 400-fold (Khersonsky et al., 2011). Directed evolution also assisted in developing KE59, a variant with limited stability that proved to be highly evolvable when, after the introduction of some consensus mutations, sixteen rounds of evolution boosted its efficiency more than 2,000-fold (Khersonsky et al., 2012). This joint effort perfectly exemplifies how directed evolution can assist in de novo enzyme design (Lutz, 2010; Kries et al., 2013).

Another case of the important progress that can be made with nonnaturally occurring enzymes refers to the Diels-Alder reaction. This is a classic example for the addition of unsaturated molecules in which the formation of two $\mathrm{C}-\mathrm{C}$ bonds takes place in a single step process. Highly valuable in organic synthesis design, the pericyclic reaction has been previously catalyzed by analogous antibodies (Yli-Kauhaluoma et al., 1995). Based on the chemistry of the reaction between 4-carboxybenzyl-trans-1,3butadiene-1-carbamate and $N, N$-dimethylacrylamide, and in order to stabilize the single cyclic transition state, a $\beta$-propeller scaffold was reconstructed, a computational effort that led to the design of DA_20_00, a variant with Diels-Alderase activity (Siegel et al., 2010). More recently, extensive optimization was carried out via directed evolution (which included the combination of parallel computational refinement with eight rounds of error-prone PCR and selection), yielding the CE20 variant with a more than 100 -fold improved $k_{\text {cat }}$ relative to the synthetic DA_20_00 enzyme (Preiswerk et al., 2014). 
The de novo design of retro-aldolases has also taken computational design to the next level, bringing transition states and intermediates of complex multistep mechanisms into consideration. In this case, the objective is to catalyze a reaction where a $\mathrm{C}-\mathrm{C}$ bond is broken (e.g. using a nonnatural substrate like 4-hydroxy-4-(6-methoxy-2-naphthyl)-2-butanone and measuring this activity through the fluorescence of the aldehyde produced). Based on one potential mechanism, Rosetta Match and Rosetta Design algorithms (Kuhlman, 2003; Zanghellini, 2006) predicted a catalytic environment for a strategically positioned Lys residue in a large hydrophobic pocket of a $\beta$-barrel scaffold (Jiang et al., 2008). Iterative cassette mutagenesis on the active site and eight rounds of directed evolution identified 17 amino acid substitutions from the parental retro-aldolase (RA95.0), providing the new RA95.5-8 enzyme with a catalytic efficiency closer to that of natural aldolases (Althoff et al., 2012; Giger et al., 2013).

Beyond adapting biocatalytic promiscuity to chemical processes, directed evolution has also expanded biological reactivity. One of the most notable examples is that considered as the first "artificial enzyme", a case study where the final variant possessed both a new biological activity and a new structure. From a non-catalytic zinc finger scaffold, a singular RNA ligase was created simply through directed evolution and without prior knowledge of the mechanism involved, so that for the first time an enzyme joined the 5' triphosphorylated extreme of an RNA molecule to the 3'hydroxyl group of a second nucleic acid (Chao et al., 2013; Seelig and Szostak, 2007). Messenger RNA display is an effective technique for the selection of proteins with new binding activities. In this process, in vitro translation takes place after the crosslinking to a 3'-puromycin nucleotide of the RNA transcribed from a DNA library. To detect the new activity, mRNA is reverse transcribed with a primer containing PPP-substrate ( $5^{\circ}$-triphosphateactivated RNA), before incubation with biotinylated HO-substrate (3'hydroxyl RNA). The cDNA of new enzymes capable of the RNA ligation reaction (Table 1) can be recovered (by biotin-streptavidin affinity) and amplified by PCR for the next round of evolution. On that account, an inactive zinc finger structure was lost during the puromycin modification when the 10C ligase, a particularly stable variant, adopted a novel 3D structure. Using mRNA display for selection, several active variants were identified with an estimated $2 \times 10^{6}$-fold improvement.

The ad-hoc design of enzymes to fit within non-biocatalytic reactions is limited by the still obscure relationship between amino acid sequence and protein function. When they are unable to achieve acceptable levels of efficiency, the adequate development of de novo biocatalysts still means they must undergo a series of cycles of mutagenesis and selection (Brustad and Arnold, 2011). Since directed evolution operates as a vector, with a magnitude and direction, new enzymatic processes could be based on any minimal conversion (Renata et al., 2015). Thus, the quest for new activities will depend on the engineering of stable and promiscuous enzymes, hence the current interest in ancestral proteins that combine both these features (Huang et al., 2012; Alcalde, 2015). 


\section{Unnatural amino acids and artificial DNA}

\subsection{Unnatural amino acids}

There are several advantages that can be obtained from the incorporation of unnatural amino acids into proteins, particularly with respect to the creation of antibodies with increased affinities or bi-specificity, antibody drug conjugates (e.g. to direct potent anti-cancer drugs to the site of the tumor to avoid systemic toxicity), affibodies (designed to bind protein targets, with benefits for randomized libraries of mutants) or protein scaffolds (Wals and Ovaa, 2014). Several directed evolution approaches have been adopted for this purpose, such as the evolution of Ribo-X, an orthogonal ribosome selected for efficient decoding of the amber codon. The three natural stop codons in RNA are: UAG ("amber" codon), UAA ("ochre" codon) and UGA ("opal" codon). In this laboratory approach, the amber codon was redefined so that it was not interpreted as the end of protein translation (Wang et al., 2007). To augment the capacity to incorporate unnatural amino acids into proteins, 11 libraries were created by saturation mutagenesis of a $16 \mathrm{~S}$ ribosomal RNA to discover variants that maintained the aforementioned decoding ability for the amber codon and that could also decode quadruplet codons on the orthogonal mRNA (Neumann et al., 2010). Ribo-Q1 (with two adjacent mutations, A1196G and A1197G) was identified, showing almost the same efficiency in decoding quadruplets as triplets, without losing its amber codon decoding properties. In fact, this new orthogonal ribosome displayed the same fidelity for triplet and quadruplet translation as the wild type ribosomes. Orthogonal amino acyl-tRNA synthetase-tRNA pairs can also be evolved (Chin et al., 2002; Neumann et al., 2010), so that when used in conjunction with orthogonal ribosomes engineered by directed evolution, they might provide a system capable of incorporating more than 200 combinations of unnatural amino acids into proteins (Fig. 2).

The use of unnatural amino acids to locate probes for the biophysical study of molecules is one milestone in molecular imaging only possibly achieved with the contribution of laboratory evolution. Structural protein studies can be conducted with the use of Föster resonance energy transfer (FRET) technology as an estimation of the distance between two chromophores sited in the molecule. A recent example is the monitoring of conformational changes on calmodulin (CaM). An evolutionary approach was taken with the creation of pyrrolysyl-tRNA libraries by saturation mutagenesis to select variants to decode quadruplet codons on previously engineered ribosome ribo-Q1 (Neumann et al., 2010). Within the selection of a dozen of unnatural amino acids successfully incorporated, those encoding tetrazine and norbornene functionalities were labeled with fluorophores for FRET analysis. The CaM conformational change was possible when fluorophores movements upon denaturalization with the addition of urea were consistent with FRET signaling (Wang et al., 2014). Measuring bioluminescence is also a powerful technology for the molecular imaging of biological processes. Visible-light fusion reporters have been created as conjugates of Gaussia princeps luciferase (GLuc) and single chain antibody 
fragments for ex vivo surface marking of tumor cells. Accordingly, a cell-free protein synthesis platform was set up overcoming the hurdle of unnatural amino acid cell membrane crossing. To obtain the probe by covalent coupling, in vitro evolved aminoacyl-tRNA synthetase/tRNA pair from Methanococcus jannaschi (Wang et al., 2001) was used for the site specific incorporation of unnatural amino acid p-azido-L-phenylalanine (AZF) in the antibody fragment. Conjugation takes place by azide-alkyne click reaction after the substitution of methionine residues from GLuc with Lhomopropargylglycine (Patel et al 2009).

These studies serve to illustrate the great potential of UAA with uses in different fields that surely will be farther expanded in the near future.

\subsection{Unnatural DNA}

DNA polymerases catalyze the assembly of one of the most important biopolymers in nature. For billions of years these enzymes have set the pace for the expansion of life, driving natural evolution by permitting just the right degree of inaccuracy. It is this colossal exercise of evolution that we now attempt to continue on the laboratory bench. Moreover, nucleic acids are considered as valuable polymers that can be modified, obtaining the so called XNAs (xeno-nucleic acids) that are not found in nature (Pinheiro et al., 2012). These XNAs offer us great opportunities in applications such as sequencing, microarrays, fluorescent in situ hybridization, re-usable diagnostics, therapeutics, nanostructures and materials, catalysts, highaffinity ligands, SELEX (systematic evolution of ligands by exponential enrichment) or by producing unnatural codons to direct the incorporation of unnatural amino acids into proteins (Pinheiro et al., 2012; Chen and Romesberg, 2014; Pinheiro and Holliger, 2014). Although nucleic acids are promising nanoscale building materials, precisely because of their capacity to evolve, they show certain chemical and biological unstability whereas their chemical diversity is too limited for real applied uses, in part due to the extremely high substrate specificity of DNA polymerases. Accordingly, the ability to introduce modified nucleotides and create XNA is a strategy that might enable this material to adapt to current demands. In recent years, several such successful examples have come to light. For instance, a DNA polymerase of the polB-family from Pyrococcus furiosus (Pfu) has been evolved by short-patch compartmentalized self-replication (spCSR) until it was capable of generating "CyDNA", a XNA in which every deoxy cytosine triphosphate (dCTP) was substituted by a cyanine dye-dCTP (Cy3- or Cy5dCTP) via PCR (Ramsay et al., 2010). The discovery of this E10 variant was quite remarkable given the poor capacity of polymerases to use Cy-dye labeled nucleotide triphosphates as substrates, at least for high density substitution. E10 was even capable of producing CyDNA probes up to $3 \mathrm{~kb}$, 20 -fold longer than those produced with commercial Klenow polymerase. The resulting CyDNA displayed highly specific target DNA binding, resistance to some endonucleases, loss of silica and intercalating dye binding and a bulkier apparent diameter. CyDNA can serve as a photoswitchable biopolymer for quenching, excimer fluorescence enhancement or chromatic shifting (Ramsay et al., 2010; Pinheiro et al., 2014; Smith et al., 2012). 
In another case study, a TgoT variant of the replicative Thermococcus gorgonarius polymerase was subjected to random and phylogenetic diversity, and compartmentalized self-tagging (CST) selection, generating the Pol6G12 variant (Pinheiro et al., 2012). This mutant had HNA (1,5-anhydrohexitol nucleic acid) polymerase activity capable of synthesising HNA from DNAtemplates with lengths that allow the codification of significant genetic units, such as tRNA genes. Moreover, starting from TgoT and using statistical correlation analysis (SCA) and random mutagenesis, RT521 was seen to be an accomplished HNA reverse transcriptase, opening the way to replicating the information encrypted in those HNAs. In addition, four other polymerase variants were encountered that together with the aforementioned enzymes, could synthesize and reverse transcribe another five XNAs. Following up on these ground-breaking studies will shed light on the parameters that govern the encoding of genetic information, as well as serving to develop tools with customized physicochemical properties (such as stronger hybridization or resistance to nucleases or acidic $\mathrm{pH}$ ) better suited to biotechnology and medical applications (Pinheiro and Holliger, 2014).

The artificially expanded genetic information system (AEGIS) broadens the genetic alphabet far beyond the limits of the four letter code imposed by nature (Piccirilli et al., 1990; Geyer et al., 2003; Henry et al., 2003). These "freak" nucleobases have different hydrogen bond patterns to the natural ones, they are orthogonal and pair specifically. In an evolution experiment, Taq DNA polymerase variants were sought that were capable of incorporating dZTP (6-amino-5-nitro-3-(1'- $\beta$-D-2'-deoxyribofuranosyl)-2(1H)-pyridone) opposite to $\mathbf{P}$ (2-amino-8-(1'- $\beta$-D-2'-deoxyribofuranosyl)imidazo[1,2-a]-1,3,5triazin-4(8H)-one) in a template (Laos et al., 2013). The Z:P pair is joined by three hydrogen bonds, although the arrangement of the donor and acceptor groups implicated differs to that of C:G. Random mutations were introduced into the polymerases and CSR (compartmentalized self-replication) plus nested PCR was used to enrich for the desired features (using real-time PCR to detect those that best incorporate $\mathbf{Z}: \mathbf{P}$ pairs). Two leading variants were selected with a strong capacity to synthesize duplex DNA containing the selected AEGIS pair. However, these variants were not so good at incorporating dPTP when $\mathbf{Z}$ was present in the template, so they represent "unidirectional" polymerases that are somewhat rare in nature. Among the applications proposed for AEGIS are the monitoring of viral loads in infected patients or for creating robotic probes for the NASA that can travel to outer space (Collins et al., 1997; Benner et al., 2003).

Nucleosides can also be supplanted by nucleoside analogs (NAs), promising prodrugs for antiviral and cancer treatment. Nucleosides possess the capability of crossing the cellular membrane into the intracellular medium. Once there, they are phosphorylated by endogenous kinases obtaining the form of the active drug (the phosphorylated states are unable to cross the membrane). Kinases act inefficiently on NA when compared to natural nucleosides, a hindrance to their clinical application. The chemically synthesized triphosphate form of ddT (3'-deoxythymidine) is a very good inhibitor of cellular and viral DNA polymerases in vitro (Fisher et al., 1994), 
an effect that was not retained when tested in vivo (Balzarini et al., 1987). To unlock this therapeutic pathway, random mutagenesis and DNA shuffling of the Drosophila melanogaster 2'-deoxynucleoside kinase (DmdNK) was performed to select for orthogonal kinases with altered substrate specificity (Liu et al., 2009). In order to be able to employ fluorescence activated cell sorting (FACS) as a selection method, fluorescent 3'-deoxythymidine (fddT) was used to mimic the effects of the variants on ddT. In this way the R4.V3 variant was isolated, which proved to be more efficient in vivo where it enhanced NA phosphorylation by eliminating the competition of the natural 2'-deoxynucleoside. Thus, this directed evolution-FACS approach appears to provide good opportunities to develop and implement efficient treatments against viral infections and cancer.

By following these research leads, some light will be shed on how genetic information is encoded, as well as serving to develop tools with adhoc properties for biotechnology and medicine.

\section{Applications at the cutting edge of biotechnology}

\subsection{Enzyme bioremediation}

Since humanity became capable of modifying natural compounds or even of chemically synthesizing new ones, the number of anthropogenic xenobiotic- contaminants has increased dramatically (Ang et al., 2005). One of the first strategies to reduce their potential toxicity and long half-life was using microorganisms to perform in situ bio-stimulation or through ex-situ technologies (e.g. land farming). Overcoming obstacles like bans concerning the use of GMOs (genetically modified organisms) in natural environments, the struggle of the microorganisms to adapt to places with more than one contaminant or the inability to degrade some non-natural compounds, is currently driving the search for new, greener solutions (Alcalde et al., 2006). Enzyme bioremediation arises as a robust alternative for the treatment of xenobiotics since there are no legal problems concerning their use in the environment and additionally, they make minimal demands to act in contaminated areas. Nevertheless, certain limitations have hindered the extensive use of enzymes in polluted areas, ranging from high production costs, the poor use of non-natural substrates or the narrow operational conditions. Unlike natural compounds, most anthropogenic pollutants have only arisen in the environment in the past 100 years. This implies that microorganisms have not been exposed to these pollutants for long enough to have adapted to them and their natural evolution has still to yield specialized enzymes, even though some exceptions can be seen where nature has taken the first steps along this path (Serdar et al., 1982; Cook et al., 1983; Seffernick and Wackett, 2001).

Engineering enzymes towards xenobiotic degradation mainly involves increasing biocatalyst promiscuity so that they accept new substrates, or even new activities can be created (Fig. 3). For example, a thermostable phosphotriesterase-like lactonase (PLL) from Geobacillus kaustophilus (GkaP) 
was designed by four rounds of rational and random mutagenesis, to transform the pesticide ethyl-paraoxon (Zhang et al., 2012b). The 26A8C variant accumulated eight mutations that lowered its natural lactonase activity but that improved its phosphotriesterase (PTE) activity (almost negligible in the wild type) to practically the same level of the PTE from Brevundimonas diminuta (BdPTE), which naturally degrades organophosphates (OPs, see below). The thermostability of the 26A8C variant was lower than that of the non-evolved one, although it was still higher than that of BdPTE. A similar study was performed with the lactonase from Deinococcus radiodurans (Dr0930), which has 60\% identity with GkaP and was also evolved towards PTE activity. The resulting protein degraded seven different OPs while retaining its natural activity towards lactones (Meier et al., 2013). Another interesting case is the degradation of polychlorobiphenyls (PCBs) by biphenyl dioxygenases (BphA). These enzymes are among the most efficient biocatalysts that attack PCBs, even though these pollutants are often a mixture of many compounds of which only a small proportion are substrates for BphA. Random mutagenesis was applied to three different regions of the BphA from Burkholderia xenovorans LB400 involved in substrate specificity. Ten different variants were identified that were capable of using three/four different PCBs that the wild type could not degrade. Furthermore, some important positions for substrate specificity were identified that can be interesting for further evolution of different arylhydroxylating dioxygenases (Zielinski et al., 2006).

These examples of enzymes with new activities or substrate specificities demonstrate that this can be successfully accomplished by combining directed evolution with rational approaches in a single structureguided evolution approach. Moreover, computational algorithms are being more and more frequently used for enzyme bioremediation. For example, the de novo design of an organophosphate hydrolase from a mononuclear zinccontaining metalloenzyme was prepared computationally using a set of mononuclear zinc enzymes. The de novo enzyme, a modified adenosine deaminase called PT3, was able to degrade the OP diethyl 7hydroxycoumarinyl phosphate. Subsequently, PT3 was subjected to directed evolution to obtain an improved variant, PT3.3, with 2,500-fold higher activity than PT3 (Khare et al., 2012). Similarly, a structural model of atrazine chlorohydrolase (AtzA) was designed computationally, an enzyme capable of degrading atrazine that is a commonly used, environmental harmful herbicide. To construct the model, the structure of the three closest relatives was combined and the resulting enzyme was similar to AtzA, except for the region of the pocket for the N-ethyl of atrazine at the active site, which was chosen for saturation mutagenesis. The library included variants with improved activity against atrazine. Moreover, the amino acid preference for the target region was elucidated and a consensus variant was obtained by site-directed mutagenesis. This variant incorporated five changes in the mature protein and it achieved a 20-fold improvement in catalytic efficiency compared to wild type AtzA (Scott et al., 2009). 
OPs can also threaten human life, attacking the nervous system, and as these compounds can be used in chemical warfare, ways to defend against them are being developed that include the use of enzymes (Nachon et al., 2013). Human butyrylcholinesterase (hBChE) is one of the favorite candidates to hydrolyze OPs because it can be administrated exogenously to humans since it is blood tolerant and active. However, its reaction with nerve agents requires some improvement as it is inactivated when it complexes with the substrate. Rational design yielded variants with slightly increased resistance to OPs but with reduced catalytic efficiency (Zhang et al., 2012a). However, evolution of this same enzyme with nerve agent analogues identified three variants with increased resistance to these compounds while retaining high catalytic efficiency. Mutations were located far from the active site, the predicted area for rational design, which may explain the differences between the mutants obtained by rational and directed evolution approaches (Dwyer et al., 2014). PTE is also a promising enzyme for OP nerve agent degradation. Designing a PTE able to attack $\mathrm{S}_{\mathrm{p}}$-enantiomers, the most toxic forms of these OPs, instead of hydrolyzing the $R_{p}$-enantiomers is challenging, and rational and directed evolution strategies have been combined to render a set of active PTE variants (Tsai et al., 2010). After generating an additional set of libraries, the best mutants were characterized based also on previous studies using real nerve agents. As far as we are concerned, the YT variant was the best PTE for the detoxification of nerve agents reported to date. This mutant displayed improved activity against the $\mathrm{S}_{\mathrm{p}}$-enantiomers of gases like sarin, soman and cyclosarin (Tsai et al., 2012).

We are aware that there is still much work to do in the field of enzyme bioremediation, yet these results demonstrate that efforts are heading in the right direction. In the forthcoming years, we foresee that some of these evolved enzymes will become commercially available and they will serve to protect the environment.

\subsection{Biomedicine}

Directed evolution has added a new dimension to the design and adaptation of ad-hoc systems to physiological environments. As such, customized biomedical approaches can be seen to be effective in order to detect or even cure certain diseases, particularly in combination with more conventional therapies.

Adeno-associated viral vectors: A strategy that holds much promise in the field of biomedicine is that of replacing defective or missing genes with exogenous ones using adeno-associated viral (AAVs) vectors. Although their low pathogenicity make these vectors interesting (Kay et al., 2001), their use is limited by difficulties in surpassing physiological barriers and their poor transduction of certain cell types (Bartel et al., 2012). In recent years, directed evolution has allowed stable and selective viruses to be created that are capable of targeting diseases with great precision. This is the case of the $7 \mathrm{~m} 8$ variant, the best hit from the screening of several mutant libraries of the AAV2 serotype (over $3 \times 10^{8}$ variants) subjected to in vivo directed 
evolution. In order to prevent and reverse retinal degeneration, this mutant was capable of penetrating the vitreous humor and infecting photoreceptor cells, which makes it a potential therapeutic vector that can be applied to the damaged retina without the need for intravitreal injections (Dalkara et al., 2013). An additional example is the use of DNA shuffling with AAVs for epileptic related illnesses in order to improve selective crossing of the seizure-compromised Blood-Brain Barrier (Gray et al., 2010). After shuffling different AAV serotypes, variants 32 and 83 showed the ability to infect brain cells (main serotype 8 characteristic), while not infected non-brain related organs (main serotype 1 characteristic). These clones were subsequently improved by directed evolution to enhance the selectivity of the vectors, yielding a virus capable of introducing exogenous DNA only into cells involved in epilepsy. Moreover, the cell infectivity of the virus was improved by specific modification of the recognition site, creating a platform for the infection of stem cells (Jang, et al., 2011).

Enzymes for biomedical therapies and biodevices: Directed evolution of enzymes or viral antigens opens new avenues for biomedical applications, particularly when their potential use is limited by production costs, poor activity or even the lack of function in physiological medium. The Mycobacterium bovis BCG (Bacillus Calmette-Guérin) is a promising vaccine vector for HIV but unfortunately, functional expression of viral antigens in BCG is not straightforward as it is associated with poor genetic stability and low immunogenicity. This bottleneck was recently surpassed by directing evolution to enhance the production of the HIV antigen 3-fold over the parental type (Chapman et al., 2014). Zinc finger nucleases (ZFNs) are chimeric restriction enzymes formed by attaching the cleavage domain of an endonuclease (FCD) with site-specific, DNA binding zinc finger proteins. ZFNs have dozens of applications in gene therapy since they can achieve site specific double-strand cleavage in genes. Using mutagenesis and DNA shuffling, a highly efficient nuclease was engineered to enhance the activity of wild type FCD more than 15-fold (Guo et al., 2010).

In terms of functionality in physiological fluids, human blood, plasma or even saliva are extreme environments for enzymes used to working in acid environments with low salt content. This is the case of a fungal laccase engineered to be active in human blood when attached to the cathodic compartment of a 3D nanobiodevice. The goal of this device was to detect metabolites in vivo (glucose, $\mathrm{O}_{2}$, insulin) while extracting the information through wireless technology (Falk et al., 2014). After several rounds of directed evolution and screening in the presence of a buffer that mimicked

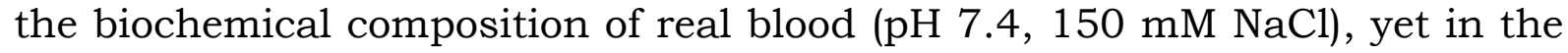
absence of coagulating agents and red cells, the ultimate laccase variant (ChU-B mutant) was active in real human blood and plasma (Mate et al., 2013). The breakdown of the properties of ChU-B highlighted the notable shift in the $\mathrm{pH}$ activity profile towards the basic side, along with improved resistance to different types of halides. 
A further example is the evolution of the arginine deiminase (ADI) that catalyzes the hydrolysis of L-arginine to L-citrulline and ammonia. This enzyme is used to treat liver cancer in auxotrofic arginine tumors cells (Ni et al., 2008). Although a commercial drug based on this biocatalyst (ADI-PEG$20)$ is available, its strict $\mathrm{pH}$-dependent activity restricts its use as the enzyme loses $80 \%$ of its activity at physiological pH ( $\mathrm{Zhu}$ et al., 2010a); besides the enzyme shows a poor substrate affinity (the $K_{\mathrm{m}}$ value for Larginine is $1.30 \mathrm{mM}, \sim 10$-fold above the concentrations present in blood) (Cheng et al., 2015). After the initial evolution modified the $\mathrm{pH}$ profile, a stable variant was generated with a 4 -fold higher $k_{\text {cat }}$ than the wild-type at $\mathrm{pH} 7.4$ (Zhu and Tee, 2010a). This variant was further evolved in order to improve the catalytic efficiency, enhancing the $k_{\text {cat }}$ over 100 -fold with respect to the parental type, while reducing the $K_{\mathrm{m}}$ to $0.35 \mathrm{mM}$, within the order of magnitude of L-arginine concentration in blood ( $\mathrm{Zhu}$ et al., 2010b; Cheng et al., 2015).

Molecular imaging and clinical diagnostics: The monitoring of clinically relevant targets by molecular imaging has attracted great attention in the medical field. The detection of certain small molecules in living cells with subcellular resolution facilitates early disease diagnosis, as well as providing information about disease mechanisms, its evolution and the response to treatment or stimuli. Therefore, much effort has focused on generating new biomolecules suitable for these purposes, some of which have successfully employed directed evolution to engineer proteins that overcome their natural restrictions to such needs. One striking example is the brilliant engineering of the heme domain of cytochrome $\mathrm{P} 450_{\mathrm{BM} 3}(\mathrm{BM} 3 \mathrm{~h})$ to specifically bind dopamine, a neurotransmitter involved in a number of mental processes like learning, reward and motor coordination, and that is also associated with neurodegenerative diseases and addiction (Shapiro et al., 2010). Changes in $\mathrm{T} 1$ relaxivity (a standard measure of the strength of the contrast agent) due to ligand binding made it possible to use BM3h as a contrast agent in magnetic resonance imaging (MRI). Through five rounds of directed evolution, two variants were obtained, BM3h-8C8 and BM3h-B7, with 100 to 300-fold higher affinity for dopamine and with a 100-fold lower affinity for arachidonic acid (its natural ligand), and with an enhancement in relaxivity greater than 2-fold (Fig. 4A). The newly evolved dopamine sensors were successfully implemented in model experiments to detect dopamine release in living mammalians cells and in the brain of live animals by MRI (Shapiro et al., 2010). Affinity for other neuroactive molecules like norepinephrine and serotonin was also reported, suggesting that the engineered sensors can be further evolved to enhance their selectivity for other molecules. Accordingly, a comprehensive study of the ligand binding pocket of BM3h variants was carried out by iterative site-saturation mutagenesis. These authors combined directed evolution with rational approaches to fine tune highly selective dopamine and serotonin MRI contrast agents. Thus, a variant was obtained (BM3-9D7) with improved affinity (over 760-fold), ligand specificity (over 50fold preference with respect to serotonin) and enhanced relaxivity (94\% of longitudinal relaxation rate) for dopamine compared to the wild type BM3h. A biosensor was also reported for the first time with high affinity for 
serotonin within physiological conditions in the brain (variant BM3-2G9C6), with a dissociation constant $\left(K_{d}\right)$ of $700 \mathrm{nM}(3,900$-fold better than the wild type BM3h), increased selectivity (over 250-fold with respect to dopamine and norepinephrine) and high relaxivity (94\% of longitudinal relaxation rate) (Brustad et al., 2012).

Recently, the evolution of rhodopsin from Gloeobacter violaceus (GR) revealed how variation in spectral properties is determined by the protein sequence. This type of proton pumping rhodopsin (PPR) transmembrane protein can be used for optoelectronics, as described below (see section 5.3), although in this case the focus was on bioenergy, optogenetics and live cellimaging applications. A set of variants were obtained with absorption maxima $\left(\lambda_{\max }\right)$ between 458 and $619 \mathrm{~nm}$, exceeding the limits of known PPRs (Fig. 4B). However, the natural activity (proton pump) of those variants with a $\lambda_{\max }$ above that of the known PPRs was suppressed. Interestingly, among these engineered mutants, that with highest red shift was also the most brightly fluorescent evolved GR. A high red fluorescent GR was detected and it can be used as a potential starting point to further develop opsin-based biosensors (Engqvist et al., 2015). Along similar lines, the Archaerhodopsin-3 (Arch) of halobacterium Halorubrum sodomense was also modified, introducing the mutations from the evolved fluorescent GR. Not only was its fluorescence improved but also, the $\lambda_{\max }$ was shifted by $70 \mathrm{~nm}$. Similarly, the directed evolution approaches were coupled to site-saturation mutagenesis to improve Arch brightness more than 20-fold. This new Arch variant (DETC) was successfully used to detect voltage changes in mammalian cells and such an improved Arch can be employed in cell-imaging and physiological sensing (McIsaac et al., 2014).

Another success story involves the directed evolution of APEX, a monomeric peroxidase derived from the homodimeric pea and soybean ascorbate peroxidase (Martell et al., 2012). APEX is more suited to protein imaging than other peroxidases given its small size with less structural complexity (monomeric), and the fact that it is active in intracellular compartments. Despite its potential in protein imaging, its low sensitivity has limited its use and indeed, APEX activity was barely detectable when expressed weakly. It was proposed that this low sensitivity might be due to poor stability and/or weak heme binding, and directed evolution was employed to tackle this problem. An APEX library was created, and yeast surface display coupled with FACS was employed to detect improved variants with enhanced activity. APEX2 performed better than APEX in protein imaging in cells using electron microscopy (EM) and in proteomic enrichment experiments. Further analysis showed that APEX2 was slightly more thermostable than APEX and it incorporated heme slightly better. Interestingly, the enhanced activity of APEX2 could not be totally justified by these minor changes in stability and heme binding. Relatively low concentrations of $\mathrm{H}_{2} \mathrm{O}_{2}$ compared with those concentrations used in experiments strongly inhibited APEX, whereas APEX2 was more stable than APEX in the presence of peroxide, explaining its improved sensitivity relative to APEX. Using the directed evolution approach, the APEX peroxidase was 
easily tuned. Moreover, the localization of MICU (a calcium uptake regulatory protein) to the inner mitochondrial membrane was achieved by fusing APEX2 to MICU (Lam et al., 2015). Therefore, APEX2 can now be used to resolve the subcellular localization of different targets.

Due to its high $\beta$-D-glucose specificity and stability, glucose oxidase (GOx) can be used to monitor diabetes through amperometric glucose test strips. However, the main drawback is its oxygen dependent activity that produce errors in the readings from the amperometric device. Recently, the GOx from Aspergillus niger was engineered to become oxygen independent by switching the electron acceptor preference from oxygen to a quinone diamine mediator (QDM) (Arango Gutierrez et al., 2013). Two rounds of directed evolution followed by site-saturated mutagenesis coupled to QDM screening generated the V7 variant that accumulated four mutations. This evolved variant had 37 -fold lower oxygen-dependent activity while retaining $\beta$-Dglucose specificity and thermostability. A comprehensive study of the mutated positions revealed their functional implications in the mediator and in oxygen activity.

Other recent experiments described how an albumin-binding domain (ABD) present in streptococcal Protein G was tailored to have high affinity for tumor-associated proteins, such as epidermal growth factor receptor 3 (ERBB3) (Nilvebrant et al., 2013) and epidermal growth factor receptor 2 (ERBB2) (Nilvebrant et al., 2014) while albumin affinity could be tuned. Phage- and cell-display systems were combined with combinatorial mutagenesis to obtain small proteins with bispecific affinity towards tumorassociated targets and with enhanced binding affinities in the nanomolar range, these having potential application in cancer diagnostics and therapy.

The trypsin inhibitor-II from Ecballium elaterium (EETI-II), a knottin peptide present in the seeds of the squirting cucumber, was engineered to bind to the integrin $\alpha_{v} \beta_{3}, \alpha_{v} \beta_{5}$ and $a_{5} \beta_{1}$ receptors (Kimura et al., 2009). These three integrin receptors are expressed strongly at the surface of a variety of cancer cells and they are involved in tumor development, influencing survival, invasion and angiogenesis (Desgrosellier and Cheresh, 2010). Rational design was combined with directed evolution to generate two combinatorial libraries in which the native trypsin binding region is replaced by two Arg-Gly-Asp (RGD) integrin binding motifs from fibronectin flanked by random sequences. Two rounds of directed evolution coupled with six rounds of FACS identified three mutants $(1.5 \mathrm{~B}, 2.5 \mathrm{D}$ and $2.5 \mathrm{~F})$ with affinity for integrin receptors at nanomolar levels. The evolved mutants $1.5 \mathrm{~B}$ and 2.5D targeted $\mathrm{a}_{\mathrm{v}} \beta_{3}$ and $\mathrm{a}_{\mathrm{v}} \beta_{5}$, and they were able to bind to U87MG (glioblastoma) cells with high affinity and inhibit their adhesion to vitronectin-coated plates. However, the $2.5 \mathrm{~F}$ mutant, which binds with unique specificity to $a_{v} \beta_{3}, a_{v} \beta_{5}$ and $a_{5} \beta_{1}$, also inhibited cell adhesion to fibronectin-coated plates, showing great potential to be used in molecular imaging and in clinical cancer therapeutics. For example, EETI $2.5 \mathrm{~F}$ was conjugated with a fluorescent dye and it was able to bind to medulloblastoma tumor tissue in mouse models, producing enhanced 
contrast signals when compare with other markers (Moore et al., 2013). This opens new opportunities to engineer knottins with high specificity and superior contrast capacity.

\subsection{Bionanomaterials}

By using bottom-up approaches, biocatalysts can be used to create new materials and devices. For instance, several enzymes have the capability of catalyzing reactions that lead to the formation of bioplastics, holographics or silica. A different approach to using enzymes for material applications is to allow the microorganisms to accumulate them in larger quantities, and some recent advances in this field are highlighted below.

Some microorganisms produce bioplastic precursors, such as 1hexene, 1-octene or 1-nonene, that are at the same time toxic to themselves, thereby inhibiting their growth. To overcome this toxicity, these bugs have developed strategies like the use of efflux pumps (transporters) to expel these noxious compounds. The AcrAB-TolC efflux pump from Escherichia coli was recently evolved for tolerance against the olefin precursors of bioplastics (Mingardon et al., 2015). First, the AcrAB genes were deleted from E. coli strains (TolC is not involved in tolerance towards olefins) and after error prone PCR, several mutants were found with improved growth. Specifically, the double pVar3 mutant (A279T and L822P) displayed a 1.6-fold increase in optical density after $2.5 \mathrm{~h}$ growth with $70 \mathrm{mg} / \mathrm{L}$ of 1 -hexene relative to the wild type. These and other mutations (Q584R, F617L, F927S, and F1033Y) are proof of the usefulness of evolving transporter proteins in order to increase olefin production yields.

Many bacteria use polyhydroxyalkanoates (PHAs) for energy and carbon storage, which can also be used for the manufacturing of biodegradable plastics. Among these bio-polyesters, formed by linear 3hydroxy fatty acid monomers, poly(3-hydroxybutanoate) or $\mathrm{P}(3 \mathrm{HB})$ is the most common type. Three enzymes are necessary for $\mathrm{P}(3 \mathrm{HB})$ synthesis in nature: PhaA and PhaB, which supply the 3HB monomers; and PhaC to act as a synthase. Several PhaC have been successfully evolved to improve their activity (Taguchi and Doi, 2004) and recently, PhaB from Ralstonia eutropha was evolved by error prone PCR in E. coli to produce larger amounts of $\mathrm{P}(3 \mathrm{HB})$. The best mutants were verified using Corynebacterium glutamicum as the final heterologous host and after $72 \mathrm{~h}$, the variant containing the T173S mutation accumulated 7 -fold the polymer content in weight percent relative to the wild type PhaB (Matsumoto et al., 2013). Bearing in mind the huge amount of plastic that our society consumes, these bioplastics could help avoid the increase in the islands of waste formed by this material.

The purpose of bionanotechnology is the use of biological tools or designs for engineering applications at nanoscale (individual atoms, molecules, molecular systems...). It is possible to create nanostructures from smaller units that serve as building blocks and that can be joined, giving rise to functional structures. Besides the GR evolution described 
above (section 5.2), another rhodopsin from Halobacterium salinarum was subjected to directed evolution, a bacteriorhodopsin (BR) that is a very promising light-transducing PPR to create optical memories, holographs, photovoltaic cells or artificial retinas (Wagner et al., 2013). Of all the different conformations BR can adopt, the $\mathbf{Q}$ state is that implicated in the BR branched photocycle, which represents a promising starting point for applications involving biomimetic and biophotonic devices (Ranagan et al., 2012). This $\mathbf{Q}$ conformation is very stable, with a lifespan of 5-20 years (Birge et al., 1999; Ranaghan, 2012). A key point in accommodating BR in bioelectronic applications is to improve the so called $Q_{\text {total }}$ value, a measure of the formation and reversion of the $\mathbf{Q}$ state. After six rounds of directed evolution in which region-specific semi-random mutagenesis, site-directed mutagenesis and saturation mutagenesis methods were combined, a variant that improved 70-fold the $Q_{\text {total }}$ maintaining its stability was obtained (V49A/I119T/T121S/A126T) (Wagner et al., 2013). A mutant able to convert $99 \%$ of a sample to the $\mathbf{Q}$ state was also identified, containing two new mutations (D85E-D96Q). This variant displayed the highest holographic efficiency found to date and it is stable in the conditions needed for such applications, such as $\mathrm{pH}$, and it can be included in a polyacrylamide matrix like a device (Ranaghan et al., 2014). Due to these particularly interesting characteristics, these tailored enzymes have driven a new wave of advances in optoelectronic technologies.

If we look out to sea, we can find enzymes with appealing activities for the construction of biomaterials. For instance, marine sponges make up their silica skeleton using silicateins, biomineralizing proteins that act both as enzymes that synthesize silica (silicon dioxide) and as a scaffold for the growth of the composite. Silicatein a from the marine sponge Tethya aurantia was used to create a mutant library of $2 \times 10^{8}$ variants by error prone PCR and DNA shuffling (Bawazer et al., 2012). Every single mutant was encapsulated in biomimetic mineralization vesicles capable of protein expression (Griffiths and Tawfik, 2003), and the chemical precursors for silica and titania (titanium dioxide) were added. After an appropriate incubation time to ensure mineral synthesis, the capacity of each individual mutant to form silica and titania was screened by flow sorting based on the light-scattering or fluorescence signal emitted by the vesicles. Two variants were selected that formed silica (and also titania) with characteristics that differ from that formed by the parental type, such as higher order, more dispersed metal or metalloid oxide nanoparticles and multimetallic oxide crystals.

In a different direction, the selection of randomized peptides using combinatorial phage display libraries gave rise to several sequences with binding selectivities for different inorganic semiconductor components to develop electronic or optical devices (Whaley et al., 2000). For instance, a clone was found, G1-3, with the property to bind to Gallium Arsenide crystals (GaAs) but not to Silicon crystals, while the reverse was observed for the $\mathrm{S} 1$ clone. In another experiment, phage display libraries were used to improve the binding affinity for single-walled carbon nanotubes (SWCN) of a 
two-gene system (gIII and gVIII, codifying two coat proteins of the M13 virus) (Lee et al., 2009). Two variants, EC\# 1 and EC\#2, arose from this engineering approach with adapted properties to produce nanotubes for high-power lithium-ion batteries.

There is still much potential in the field of biomaterials design by using directed evolution, as highlighted recently (Bryksin et al., 2014). One of the ideas proposed is that "replication" can be seen as "manufacturing" when referring to biomaterials developed by this methodology, adding one more advantage to its use. Consequently, these often surprising results demonstrate that solid-state materials for advance ad-hoc human technologies can be developed by employing directed evolution.

\section{Conclusions and outlook}

The power of directed evolution is being permanently challenged by the need to address key issues in modern society, from global warming to food security. Accordingly, new advances in directed evolution within the synthetic biology and metabolic engineering scenarios are being sought to meet the demands of our industrialized world. Although an extraordinary window has now been opened in front of our very eyes, allowing hundreds of biomolecules to design "prêt a port" in a manner we could never have imagined, the shortcomings of directed evolution cannot be ignored. Problems associated with library creation and exploration are hampering to achieve full coverage of the protein sequence space in an efficient manner. Indeed, the inherent mutational bias common to most of the error-prone PCR methods and the lack of reliable random-codon mutagenesis techniques are two factors that prevent us from accessing the whole protein alphabet, while the number of effective protocols for DNA recombination -with a reasonable frequency of crossover events- are still limited. More significantly, the relatively scarce use of ultrahigh-throughput screening protocols in directed evolution experiments for practical applications dictates the future research efforts that must be pursued. By contrast, the courtship between laboratory evolution and computational methods -supported by the permanent growth in sequence data bases- is blossoming. The construction of smart mutant libraries assisted by structure guided design helps narrow the sequence space to create highly efficient enzymes in a range of green processes, from non-natural chemistry to bioremediation. Thus, the directed evolution of "de novo" enzymes and ancestral proteins are beautiful examples of how to harness computational algorithms to tailor custom-made biocatalysts while reducing the timeline of a directed evolution experiment. It is also worthwhile noting the advances achieved in DNA synthesis technologies that enable complete sets of mutant libraries to be synthesized, saving resources and experimental effort. We are certainly witnessing a new twist in the use of laboratory evolution, whereby computational and experimental work is being nicely combined. In the near future, we foresee computational evolution as a necessary driver to guide experimental evolution towards smarter and more productive mutant libraries.

After more than two decades of research into laboratory evolution, it can now be appreciate how much endeavor has been directed towards 
adapting natural occurring biomolecules to human needs. While there is an increasing demand for new enzymes or full metabolic pathways with unnatural properties, directed evolution can provide us with a range of possibilities to improve existing natural scaffolds or even to create new artificial ones to drive the acquisition of activities and traits not seen in nature. Here, we have summarized the most recent examples of these enterprises, where directed evolution has served to push the functionality of natural molecules beyond what we hitherto considered as reasonable boundaries. By combining directed evolution with rational and computational approaches, a new generation of molecules with finely-tuned characteristics is being generated, bridging the gap between natural supplies and synthetic requisites. We have just started to see how powerful directed evolution is to define novel properties, some of which extend far beyond the limits imposed by nature."

\section{Acknowledgements}

The laboratory of MA gratefully acknowledges the financial support received from the EU (FP7-KBBE-2013-7-613549-INDOX, FP7-People-2013ITN-607793 and COST-Action CM1303 Systems Biocatalysis) and the Spanish Government (BIO2010-19697-EVOFACEL, BIO2013-43407-RDEWRY and CAMBIOS-RTC-2014-1777-3) projects.

\section{Declaration of interest}

The authors have no conflict of interests to declare.

\section{References}

Abatemarco J, Hill A, Alper HS. Expanding the metabolic engineering toolbox with directed evolution. Biotechnol J 2013;8:1397-410.

Alcalde M, Ferrer M, Plou FJ, Ballesteros A. Environmental biocatalysis: from remediation with enzymes to novel green processes. Trends Biotechnol 2006;24:281-7.

Alcalde M. Engineering the ligninolytic enzyme consortium. Trends Biotechnol 2015;33:155-62.

Althoff EA, Wang L, Jiang L, Giger L, Lassila JK, Wang Z, et al. Robust design and optimization of retroaldol enzymes. Protein Sci 2012;21:717-26.

Ang EL, Zhao H, Obbard JP. Recent advances in the bioremediation of persistent organic pollutants via biomolecular engineering. Enzyme Microb Tech 2005;37:487-96.

Anzenbacher P, Anzenbacherova E. Cytochromes P450: Review on their Basic Principles. Proc Indian Natl Sci Acad 2003;B69:8. 
Arango Gutierrez E, Mundhada H, Meier T, Duefel H, Bocola M, Schwaneberg U. Reengineered glucose oxidase for amperometric glucose determination in diabetes analytics. Biosens Bioelectron 2013;50:84-90.

Balzarini J, Kang GJ, Dalal M, Herdewijn P, De Clercq E, Broder S, et al. The antiHTLV-III (anti-HIV) and cytotoxic activity of 2',3'-didehydro-2',3'dideoxyribonucleosides: a comparison with their parental 2',3'dideoxyribonucleosides. Mol Pharmacol 1987;32:162-7.

Bar-Even A, Noor E, Savir Y, Liebermeister W, Davidi D, Tawfik DS, Milo R. The moderately efficient enzyme: evolutionary and physicochemical trends shaping enzyme parameters. Biochemistry 2011;50:4402-10.

Bartel MA, Weinstein JR, Schaffer DV. Directed evolution of novel adenoassociated viruses for therapeutic gene delivery. Gene Ther 2012;19:694700.

Bartoli G, Bencivenni G, Dalpozzo R. Asymmetric cyclopropanation reactions. Synthesis 2014;46:000A-00AY.

Bawazer LA, Izumi M, Kolodin D, Neilson JR, Schwenzer B, Morse DE. Evolutionary selection of enzymatically synthesized semiconductors from biomimetic mineralization vesicles. P Natl Acad Sci USA 2012;109:E1705-14.

Benner SA, Hutter D, Sismour AM. Synthetic biology with artificially expanded genetic information systems. From personalized medicine to extraterrestrial life. Nucleic Acids Res Suppl 2003:125-6.

Benner SA, Sassi SO, Gaucher EA. Molecular paleoscience: systems biology from the past. Adv Enzymol Relat Areas Mol Biol 2007;75:1-132.

Birge RR, Gillespie NB, Izaguirre EW, Kusnetzow A, Lawrence AF, Singh D, et al. Biomolecular Electronics: Protein-Based Associative Processors and Volumetric Memories. J Phys Chem B 1999;103:10746-66.

Bloom JD, Arnold FH. In the light of directed evolution: pathways of adaptive protein evolution. Proc Natl Acad Sci USA 2009;106:9995-10000.

Bornscheuer UT, Huisman GW, Kazlauskas RJ, Lutz S, Moore JC, Robins K. Engineering the third wave of biocatalysis. Nature 2012;485:185-94.

Brustad EM, Arnold FH. Optimizing non-natural protein function with directed evolution. Curr Opin Chem Bio 2011;15:201-10.

Brustad EM, Lelyveld VS, Snow CD, Crook N, Jung ST, Martinez FM, et al. Structure-guided directed evolution of highly selective P450-based magnetic resonance imaging sensors for dopamine and serotonin. $\mathrm{J}$ Mol Biol 2012;422:245-62. 
Bryksin AV, Brown A, Baksh MM, Finn MG, Barker TH. Learning from nature Novel synthetic biology approaches for biomaterial design. Acta Biomateralia 2014;10: 1761-69)

Carter JLL, Bekhouche M, Noiriel A, Blum LJ, Doumeche B. Directed Evolution of a Formate Dehydrogenase for Increased Tolerance to Ionic Liquids Reveals a New Site for Increasing the Stability. ChemBioChem 2014;15:2710-18.

Chin JW, Martin AB, King DS, Wang L, Schultz PG. Addition of a photocrosslinking amino acid to the genetic code of Escherichia coli. Proc Natl Acad Sci USA 2002;99:11020-24.

Chao FA, Morelli A, Iii JCH, Churchfield L, Hagmann LN, Shi L, et al. Structure and dynamics of a prim:ordial catalytic fold generated by in vitro evolution. Nat Chem Biol 2013;9:81-3.

Chapman R, Bourn WR, Shephard E, Stutz H, Douglass N, Mgwebi T, et al. The use of directed evolution to create a stable and immunogenic recombinant BCG expressing a modified HIV-1 Gag antigen. PLoS One 2014;9:e103314.

Chen KQ, Arnold FH. Tuning the activity of an enzyme for unusual environments sequential random mutagenesis of Subtilisin $E$ for catalysis in dimethylformamide. Proc Natl Acad Sci USA 1993;90:5618-5622.

Chen Z, Pereira JH, Liu H, Tran HM, Hsu NS, Dibble D, et al. Improved activity of a thermophilic cellulase, Cel5A, from Thermotoga maritima on ionic liquid pretreated switchgrass. PLoS One 2013;8:e79725.

Chen T, Romesberg FE. Directed polymerase evolution. FEBS Letters 2014;588:219-29.

Cheng F, Zhu L, Lue H, Bernhagen J, Schwaneberg U. Directed arginine deiminase evolution for efficient inhibition of arginine-auxotrophic melanomas. Appl Microbiol Biot 2015;99:1237-47.

Cobb RE, Chao R, Zhao H. Directed evolution: past, present and future. AIChE Journal 2013;59:1432-40.

Coelho PS, Brustad EM, Kannan A, Arnold FH. Olefin Cyclopropanation via Carbene Transfer Catalyzed by Engineered Cytochrome P450 Enzymes. Science 2013a;339:307-10.

Coelho PS, Wang ZJ, Ener ME, Baril SA, Kannan A, Arnold FH, et al. A serinesubstituted P450 catalyzes highly efficient carbene transfer to olefins in vivo. Nat Chem Biol 2013b;9:485-7.

Collins ML, Irvine B, Tyner D, Fine E, Zayati C, Chang CA, et al. A branched DNA signal amplification assay for quantification of nucleic acid targets below 100 molecules/ml. Nucleic Acids Res 1997;25:2979-84. 
Cook AM, Grossenbacher H, Hutter R. Isolation and cultivation of microbes with biodegradative potential. Experientia 1983;39:1191-8.

Currin A, Swainston N, Dayace PJ, Kell BD. Synthetic biology for the directed evolution of protein biocatalysts: navigating sequence space intelligently. Chem Soc Rev 2014;17:14-46

Dalby, A. Strategy and success for the directed evolution of enzymes. Curr Opin Struct Biol 2011;21:473-80.

Denard $\mathrm{CA}$, Ren $\mathrm{H}$, Zhao $\mathrm{H}$. Improving and repurposing biocatalysts via directed evolution. Curr Opin Chem Biol 2015;25:55-64.

Dalkara D, Byrne LC, Klimczak RR, Visel M, Yin L, Merigan WH, et al. In vivodirected evolution of a new adeno-associated virus for therapeutic outer retinal gene delivery from the vitreous. Sci Transl Med 2013;5:189ra76.

Damborsky J, Brezovsky J. Computational tools for designing and engineering enzymes. Curr Op Chem Biol 2014; 19: 8-16.

Desgrosellier JS, Cheresh DA. Integrins in cancer: biological implications and therapeutic opportunities. Nat Rev Cancer 2010;10:9-22.

Dwyer M, Javor S, Ryan DA, Smith EM, Wang B, Zhang J, et al. Novel Human Butyrylcholinesterase Variants: Toward Organophosphonate Detoxication. Biochemistry 2014;53:4476-87.

Engqvist MKM, McIsaac RS, Dollinger P, Flytzanis NC, Abrams M, Schor S, et al. Directed Evolution of Gloeobacter violaceus Rhodopsin Spectral Properties. J Mol Biol 2015;427:205-20.

Falk M, Alcalde M, Bartlett P, De Lacey A, Gorton L, Gutierrez-Sanchez, et al. Selfpowered wireless carbohydrate/oxygen sensitive biodevice based on radio signal transmission. PLoS One 2014;9:e109104.

Farwell CC, McIntosh JA, Hyster TK, Wang ZJ, Arnold FH. Enantioselective Imidation of Sulfides via Enzyme-Catalyzed Intermolecular Nitrogen-Atom Transfer. J Am Chem Soc 2014;136:8766-71.

Fisher MA, Yadav PNS, Yadav J, Kristol D, Arnold E, Modak MJ. Identification of a pharmacophore for nucleoside analog inhibitors directed at HIV-1 reverse transcriptase. J Mol Recognit 1994;7:211-4.

Geyer CR, Battersby TR, Benner SA. Nucleobase Pairing in Expanded WatsonCrick-like Genetic Information Systems. Structure 2003;11:1485-98.

Giger L, Caner S, Obexer R, Kast P, Baker D, Ban N, et al. Evolution of a designed retro-aldolase leads to complete active site remodeling. Nat Chem Biol 2013;9:494-8. 
Grande PM, de Maria PD. Enzymatic hydrolysis of microcrystalline cellulose in concentrated seawater. Bioresour Technol 2012;104:799-802.

Gray SJ, Blake BL, Criswell HE, Nicolson SC, Samulski RJ, McCown TJ. Directed Evolution of a Novel Adeno-associated Virus (AAV) Vector That Crosses the Seizure-compromised Blood-Brain Barrier (BBB). Mol Ther 2010;18:570-8.

Griffiths AD, Tawfik DS. Directed evolution of an extremely fast phosphotriesterase by in vitro compartmentalization. EMBO J. 2003;22:24-35.

Gupta RD, Tawfik DS. Directed enzyme evolution via small and effective neutral drift libraries. Nat Methods 2008;5:939-42.

Guo J, Gaj T, Barbas CF. Directed evolution of an enhanced and highly efficient FokI cleavage domain for zinc finger nucleases. J Mol Biol 2010;400:96-107.

Heel T, McIntosh JA, Dodani SC, Meyerowitz JT, Arnold FH. Non-natural olefin cyclopropanation catalyzed by diverse cytochrome P450s and other hemoproteins. ChemBioChem 2014;15:2556-62.

Henry AA, Romesberg FE. Beyond A, C, G and T: augmenting nature's alphabet. Curr Opin Chem Biol 2003;7:727-33.

Hernaiz MJ, Alcantara AR, Garcia JI, Sinisterra JV. Applied Biotransformations in Green Solvents. Chem Eur J 2010;16:9422-37.

Huang R, Hippauf F, Rohrbeck D, Haustein M, Wenke K, Feike J, et al. Enzyme functional evolution through improved catalysis of ancestrally nonpreferred substrates. P NatL Acad Sci USA 2012;109:2966-71.

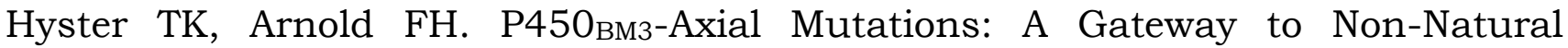
Reactivity. Isr J Chem 2015;55:14-20.

Isik M, Sardon H, Mecerreyes D. Ionic liquids and cellulose: dissolution, chemical modification and preparation of new cellulosic materials. Int $\mathrm{J}$ Mol Sci 2014;15:11922-40.

Jang JH, Koerber JT, Kim JS, Asuri P, Vazin T, Bartel M, et al. An Evolved Adenoassociated Viral Variant Enhances Gene Delivery and Gene Targeting in Neural Stem Cells. Mol Ther 2011;19:667-75.

Jiang L, Althoff EA, Clemente FR, Doyle L, Rothlisberger D, Zanghellini A, et al. De novo computational design of retro-aldol enzymes. Science 2008;319:138791.

Kay MA, Glorioso JC, Naldini L. Viral vectors for gene therapy: the art of turning infectious agents into vehicles of therapeutics. Nat Med 2001;7:33-40. 
Khare SD, Kipnis Y, Greisen P, Jr., Takeuchi R, Ashani Y, Goldsmith M, et al. Computational redesign of a mononuclear zinc metalloenzyme for organophosphate hydrolysis. Nat Chem Biol 2012;8:294-300.

Khersonsky O, Rothlisberger D, Dym O, Albeck S, Jackson CJ, Baker D, et al. Evolutionary optimization of computationally designed enzymes: Kemp eliminases of the KE07 series. J Mol Biol 2010;396:1025-42.

Khersonsky O, Rothlisberger D, Wollacott AM, Murphy P, Dym O, Albeck S, et al. Optimization of the in-silico-designed kemp eliminase KE70 by computational design and directed evolution. J Mol Biol 2011;407:391-412.

Khersonsky O, Kiss G, Rothlisberger D, Dym O, Albeck S, Houk KN, et al. Bridging the gaps in design methodologies by evolutionary optimization of the stability and proficiency of designed Kemp eliminase KE59. Proc Natl Acad Sci USA 2012;109:10358-63.

Kimura RH, Levin AM, Cochran FV, Cochran JR. Engineered cystine knot peptides that bind av $\beta 3$, av $\beta 5$, and a $5 \beta 1$ integrins with low-nanomolar affinity. Proteins 2009;77:359-69.

Kiss G, Çelebi-Ölçüm N, Moretti R, Baker D, Houk KN. Computational enzyme design. Angew Chem Int Ed 2013;52:5700-25.

Kries H, Blomberg R, Hilvert D. De novo enzymes by computational design. Curr Opin Chem Biol 2013;17:221-8.

Kuhlman B, Dantas G, Ireton GC, Varani G, Stoddard BL, Baker D. Design of a novel globular protein fold with atomic-level accuracy. Science 2003;302:1364-8.

Lam SS, Martell JD, Kamer KJ. Directed evolution of APEX2 for electron microscopy and proximity labeling. Nat Methods 2015;12:51-4.

Laos R, Shaw R, Leal NA, Gaucher E, and Benner S. Directed Evolution of Polymerases To Accept Nucleotides with Nonstandard Hydrogen Bond Patterns. Biochemistry 2013;52:5288-94.

Lee YJ, Yi H, Kim WJ, Kang K, Yun DS, Strano MS, Cede G, Belcher AM. Fabricating genetically engineered high-power lithium-ion batteries using multiple virus genes. Science 2009;324:1051-55

Lehmann C, Sibilla F, Maugeri Z, Streit WR, Dominguez de Maria P, Martinez R, et al. Reengineering CelA2 cellulase for hydrolysis in aqueous solutions of deep eutectic solvents and concentrated seawater. Green Chem 2012;14:2719-26.

Lehmann C, Bocola M, Streit W, Martinez R, Schwaneberg U. Ionic liquid and deep eutectic solvent-activated CelA2 variants generated by directed evolution. Appl Microbiol Biot 2014;98:5775-85. 
Lewis JC, Arnold FH. Catalysts on Demand: Selective Oxidations by LaboratoryEvolved Cytochrome P450 BM3. CHIMIA 2009;63:309-12.

Liu L, Li Y, Liotta D, Lutz S. Directed evolution of an orthogonal nucleoside analog kinase via fluorescence-activated cell sorting. Nucleic Acids Res 2009;37:4472-81.

Liu H, Zhu L, Bocola M, Chen N, Spiess AC, Schwaneberg U. Directed laccase evolution for improved ionic liquid resistance. Green Chem 2013;15:134855.

Lutz S. Beyond directed evolution--semi-rational protein engineering and design. Curr Opin Biotech 2010;21:734-43.

Martell JD, Deerinck TJ, Sancak Y, Poulos TL, Mootha VK, Sosinsky GE, et al. Engineered ascorbate peroxidase as a genetically encoded reporter for electron microscopy. Nat Biotech 2012;30:1143-8.

Mate D, Gonzalez-Perez D, Falk M, Kittl R, Pita M, De Lacey AL, Ludwig R, Shleev $\mathrm{S}$, Alcalde M. Blood tolerant laccase by directed evolution. ChemBiol 2013; 20: 223-231.

Matsumoto K, Tanaka Y, Watanabe T, Motohashi R, Ikeda K, Tobitani K, et al. Directed Evolution and Structural Analysis of NADPH-Dependent Acetoacetyl Coenzyme A (Acetoacetyl-CoA) Reductase from Ralstonia eutropha Reveals Two Mutations Responsible for Enhanced Kinetics. Appl Environ Microb 2013;79:6134-9.

McIntosh JA, Coelho PS, Farwell CC, Wang ZJ, Lewis JC, Brown TR, et al. Enantioselective Intramolecular C-H Amination Catalyzed by Engineered Cytochrome P450 Enzymes In Vitro and In Vivo. Chem Int Ed 2013;52:930912.

McIsaac RS, Engqvist MKM, Wannier T, Rosenthal AZ, Herwig L, Flytzanis NC, et al. Directed evolution of a far-red fluorescent rhodopsin. P Natl Acad Sci USA 2014;111:13034-9.

Meier MM, Rajendran C, Malisi C, Fox NG, Xu C, Schlee S, et al. Molecular Engineering of Organophosphate Hydrolysis Activity from a Weak Promiscuous Lactonase Template. J Am Chem Soc 2013;135:11670-7.

Mingardon F, Clement C, Hirano K, Nhan M, Luning EG, Chanal A, et al. Improving olefin tolerance and production in E. coli using native and evolved AcrB. Biotechnol Bioeng 2015;12:879-88.

Moore SJ, Hayden Gephart MG, Bergen JM, Su YS, Rayburn H, Scott MP, et al. Engineered knottin peptide enables noninvasive optical imaging of intracranial medulloblastoma. P Natl Acad Sci USA 2013;110:14598-603. 
Nachon F, Brazzolotto X, Trovaslet M, Masson P. Progress in the development of enzyme-based nerve agent bioscavengers. Chem-Biol Interact 2013;206:53644.

Neumann H, Wang K, Davis L, Garcia-Alai M, Chin JW. Encoding multiple unnatural amino acids via evolution of a quadruplet-decoding ribosome. Nature 2010;464:441-4.

Ni Y, Schwaneberg U, Sun ZH. Arginine deiminase, a potential anti-tumor drug. Cancer lett 2008;261:1-11.

Nilvebrant J, Åstrand M, Lofblom J, Hober S. Development and characterization of small bispecific albumin-binding domains with high affinity for ErbB3. Cell Mol Life Sci 2013;70:3973-85.

Nilvebrant J, Åstrand M, Georgieva-Kotseva M, Björnmalm M, Löfblom J, Hober S. Engineering of Bispecific Affinity Proteins with High Affinity for ERBB2 and Adaptable Binding to Albumin. PLoS One 2014;9:e103094.

Packer MS, Liu DR. Methods for the directed evolution of proteins. Nature 2015;16:379-94.

Patel KG, Ng PP, Kuo CC, Levy S, Levy R, Swartz JR. Cell-free production of Gaussia princeps luciferase-antibody fragment bioconjugates for ex vivo detection of tumor cells. Biochem Biophys Res Commun 2009;390:971-6.

Piccirilli JA, Krauch T, Moroney SE, Benner SA. Enzymatic incorporation of a new base pair into DNA and RNA extends the genetic alphabet. Nature 1990;343:33-7.

Pinheiro VB, Taylor AI, Cozens C, Abramov M, Renders M, Zhang S, et al. Synthetic genetic polymers capable of heredity and evolution. Science 2012;336:341-4.

Pinheiro VB, Holliger P. Towards XNA nanotechnology: new materials from synthetic genetic polymers. Trends Biotechnol 2014;32:321-8.

Pottkamper J, Barthen P, Ilmberger N, Schwaneberg U, Schenk A, Schulte M, et al. Applying metagenomics for the identification of bacterial cellulases that are stable in ionic liquids. Green Chem 2009;11:957-65.

Preiswerk N, Beck T, Schulz JD, Milovnik P, Mayer C, Siegel JB, et al. Impact of scaffold rigidity on the design and evolution of an artificial Diels-Alderase. $\mathrm{P}$ Natl Acad Sci USA 2014;111:8013-8.

Ramsay N, Jemth AS, Brown A, Crampton N, Dear P, Holliger P. CyDNA: Synthesis and Replication of Highly Cy-Dye Substituted DNA by an Evolved Polymerase. J Am Chem Soc 2010;132:5096-104. 
Ranaghan MJ Wagner NL, Sandberg MN, Birge RR. Optical applications of biomolecules. In: $M$ Large editors. Optical biomimetics: materials and applications. Cambridge, UK: Woodhead Publishing; 2012. P. 20-78.

Ranaghan MJ, Greco JA, Wagner NL, Grewal R, Rangarajan R, Koscielecki JF, et al. Photochromic Bacteriorhodopsin Mutant with High Holographic Efficiency and Enhanced Stability via a Putative Self-Repair Mechanism. ACS Appl Mater Interfaces 2014;6:2799-808.

Renata H, Wang ZJ, Arnold FH. Expanding the Enzyme Universe: Accessing NonNatural Reactions by Mechanism-Guided Directed Evolution. Chem Int Ed 2015;54:3351-67.

Reetz, MT. Laboratory evolution of stereoselective enzymes: A prolific source of catalysts for asymmetric reactions. Angew Chem Int Ed 2010;49:2-39.

Rothlisberger D, Khersonsky O, Wollacott AM, Jiang L, DeChancie J, Betker J, et al. Kemp elimination catalysts by computational enzyme design. Nature 2008;453:190-5.

Romero PA, Arnold FH. Exploring protein fitness landscapes by directed evolution. Nat Rev Mol Cell Biol 2009;10:866-76.

Scott C, Jackson CJ, Coppin CW, Mourant RG, Hilton ME, Sutherland TD, et al. Catalytic Improvement and Evolution of Atrazine Chlorohydrolase. Appl Environ Microbiol 2009;75:2184-91.

Seelig B, Szostak JW. Selection and evolution of enzymes from a partially randomized non-catalytic scaffold. Nature 2007;448:828-31.

Seffernick JL, Wackett LP. Rapid evolution of bacterial catabolic enzymes: a case study with atrazine chlorohydrolase. Biochemistry 2001;40:12747-53.

Serdar CM, Gibson DT, Munnecke DM, Lancaster JH. Plasmid Involvement in Parathion Hydrolysis by Pseudomonas diminuta. Appl Environ Microbiol 1982;44:246-9.

Shapiro MG, Westmeyer GG, Romero PA, Szablowski JO, Kuster B, Shah A, et al. Directed evolution of a magnetic resonance imaging contrast agent for noninvasive imaging of dopamine. Nat Biotechnol 2010;28:264-70.

Shivange AV, Marienhagen J, Mundhada H, Schenk A, Schwaneberg U. Advances in generating functional diversity for directed protein evolution. Curr Opin Chem Biol 2009;13:19-25.

Siegel JB, Zanghellini A, Lovick HM, Kiss G, Lambert AR, St Clair JL, et al. Computational design of an enzyme catalyst for a stereoselective bimolecular Diels-Alder reaction. Science 2010;329:309-13. 
Smith DA, Holliger P, Flors C. Reversible Fluorescence Photoswitching in DNA. J Phys Chem B 2012;116:10290-3.

Smith EL, Abbott AP, Ryder KS. Deep Eutectic Solvents (DESs) and Their Applications. Chem Rev 2014;114:11060-82.

Song, J.K. y Rhee, J.S. Enhancement of stability and activity of phospholipase A(1) in organic solvents by directed evolution. Biochim Biophys Acta 2001;1547:370-378.

Taguchi S, Doi Y. Evolution of polyhydroxyalkanoate (PHA) production system by "enzyme evolution": successful case studies of directed evolution. Macromol Biosci. 2004;4:146-56.

Tee KL, Wong TS. Polishing the craft of genetic diversity creation in directed evolution. Biotechnol Adv 2013; 1707-1721.

Tracewell CA, Arnold FH. Directed enzyme evolution: climbing fitness peaks one amino acid at a time. Curr Opin Chem Biol 2009;13:3-9.

Tsai PC, Bigley A, Li Y, Ghanem E, Cadieux CL, Kasten SA, et al. Stereoselective Hydrolysis of Organophosphate Nerve Agents by the Bacterial Phosphotriesterase. Biochemistry 2010;49:7978-87.

Tsai PC, Fox N, Bigley AN, Harvey SP, Barondeau DP, Raushel FM. Enzymes for the homeland defense: optimizing phosphotriesterase for the hydrolysis of organophosphate nerve agents. Biochemistry 2012;51:6463-75.

Verma R., Schwaneberg U., Roccatano D. Computer-aided protein directed evolution: a review of web servers, databases and other computational tools for protein engineering. Comput Struct Biotechnol J 2012;2:e201209008.

Wagner NL, Greco JA, Ranaghan MJ, Birge RR. Directed evolution of bacteriorhodopsin for applications in bioelectronics. J R Soc Interface 2013;10:20130197.

Wals K, Ovaa H. Unnatural amino acid incorporation in E. coli: current and future applications in the design of therapeutic proteins. Front Chem 2014;2:15.

Wang L, Schultz PG. A general approach for the generation of orthogonal tRNAs. Chem Biol 2001;8:883-890.

Wang K, Neumann H, Peak-Chew SY, Chin JW. Evolved orthogonal ribosomes enhance the efficiency of synthetic genetic code expansion. Nat Biotech 2007;25:770-7.

Wang M, Si T, Zhao H. Biocatalyst development by directed evolution. Bioresour Technol 2012;115:117-25. 
Wang ZJ, Renata H, Peck NE, Farwell CC, Coelho PS. and Arnold FH. Improved Cyclopropanation Activity of Histidine-Ligated Cytochrome P450 Enables the Enantioselective Formal Synthesis of Levomilnacipran. Angew Chem 2014a;126:6928-31.

Wang K, Sachdeva A, Cox DJ, Wilf NM, Lang K, Wallace S, Mehl RA, Chin JW. Optimized orthogonal translation of unnatural amino acids enables spontaneous protein double-labelling and FRET. Nat Chem 2014b;6:393403.

Welton T. Room-Temperature Ionic Liquids. Solvents for Synthesis and Catalysis. Chem Rev 1999;99:2071-84.

Whaley RS, English DS, Hu EL, Barbara PF, Belcher AM. Selection of peptides with semiconductor binding specifity for directed nanocrystal assembly. Lett Nature 2010;405: 665-8.

Wong TS, Arnold FH, Schwaneberg U. Laboratory evolution of cytochrome P450BM-3 monooxygenase for organic cosolvents. Biotechnol Bioeng 2004;85:351-358.

Yli-Kauhaluoma JT, Ashley JA, Lo CH, Tucker L, Wolfe MM, Janda KD. AntiMetallocene Antibodies: A New Approach to Enantioselective Catalysis of the Diels-Alder Reaction. J Am Chem Soc 1995;117:7041-7.

Yu Y, Lutz S. Circular permutation: a different way to engineer enzyme structure and function. Trends Biotechnol 2011;29:18-25.

Zanghellini A, Jiang L, Wollacott AM, Cheng G, Meiler J, Althoff EA, et al. New algorithms and an in silico benchmark for computational enzyme design. Protein Sci 2006;15:2785-94.

Zhang J, Chen S, Ralph EC, Dwyer M, Cashman JR. Identification of human butyrylcholinesterase organophosphate-resistant variants through a novel mammalian enzyme functional screen. $J$ Pharmacol Exp Ther 2012a;343:673-82.

Zhang Y, An J, Ye W, Yang G, Qian ZG, Chen HF, et al. Enhancing the promiscuous phosphotriesterase activity of a thermostable lactonase (GkaP) for the efficient degradation of organophosphate pesticides. Appl Environ Microbiol 2012b;78:6647-55.

Zhu L, Tee KL, Roccatano D, Sonmez B, Ni Y, Sun ZH, et al. Directed evolution of an antitumor drug (arginine deiminase PpADI) for increased activity at physiological pH. ChemBioChem 2010a;11:691-7.

Zhu L, Verma R, Roccatano D, Ni Y, Sun ZH, Schwaneberg U. A potential antitumor drug (arginine deiminase) reengineered for efficient operation under physiological conditions. ChemBioChem 2010b;11:2294-301. 
Zielinski M, Kahl S, Standfuss-Gabisch C, Camara B, Seeger M, Hofer B. Generation of novel-substrate-accepting biphenyl dioxygenases through segmental random mutagenesis and identification of residues involved in enzyme specificity. Appl Environ Microbiol 2006;72:2191-9.

Zumarraga, M., Bulter, T., Shleev, S., Polaina, J., Martinez-Arias, A.,Plou, F.J., Ballesteros, A. and Alcalde, M. In vitro evolution of a fungal laccase in high concentrations of organic cosolvents. ChemBiol 2007;14: 1052-1064. 


\section{FIGURE LEGENDS}

Figure 1. Exploring the limits of the biotechnological rainbow. Directed evolution draws on enzymes and other biomolecules that usually fulfill their biological role within the laws of nature, adapting their activity to unnatural environments and reactions. Guided by Darwin's algorithm of evolution, the capacity to adapt enzymes so that they can assist in the creation of novel materials, nanodevices and sensors is now a reality. This powerful engineering tool can modulate molecular vectors in cutting edge therapies. In conjunction with the computational design of new catalysts, in vitro evolution opens the way to generate previously unforeseen activities. In this way, the array of tools for chemical synthesis and degradation is hugely broadened, aiding our steps towards the new undertaking of a greener society.

Figure 2. Insertion of unnatural amino acids into a protein by directed evolution. Directed evolution can be applied to "hijack" the basic biological code by incorporating novel building blocks into macromolecules. Within the new family of unnatural amino acids (UAAs) we find $p$-benzoyl- $L$ phenylalanine (Bpa), a molecule with photocrosslinking properties that has been successfully incorporated into an in vitro evolved Bpa-tRNA

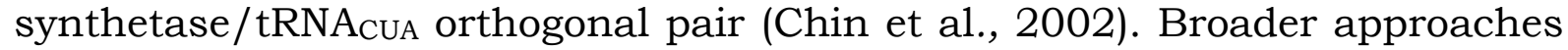
must be taken to harness the complexity of protein biosynthesis, such as the evolution of the orthogonal ribosome ribo-Q1 that not only leads to effective decoding of the amber codon into Bpa molecules but also, the efficient recognition of a set of quadruplets codons (Neumann et al., 2010).

Figure 3. Enzymatic bioremediation by directed evolution. More sustainable horizons are possible with the in vitro optimization of new enzymatic degradation processes. Many xenobiotics like polychlorinated biphenyls (PCBs), polycyclic aromatic hydrocarbons (PAHs) and organophosphates (OPs), as well as pesticides and nerve agents, can now be bioremediated, in this way erasing the synthetic footprint human activity leaves on the planet.

Figure.4. Directed evolution in biomedicine. A) To obtain protein-based MRI sensors, the heme domain of cytochrome $\mathrm{P}^{450} \mathrm{~B}_{\mathrm{BM}} 3$ was engineered to improve its ligand-binding affinity with dopamine. The neurotransmitter released after cell stimulation with $\mathrm{K}^{+}$can be measured after binding with the evolved variant BM3h-8C8 as a MRI signal based on the $\mathrm{T} 1$ relaxivity caused by the interaction. B) Opsins have raised high expectations as biotechnological tools on account of their properties as light-sensor proteins. Directed evolution was applied on Gloeobacter violaceus rhodopsin (GR) and different shifts on the offspring set the maximum of absorbance throughout a broad segment of the spectrum. Modified from (Engqvist et al., 2015). 


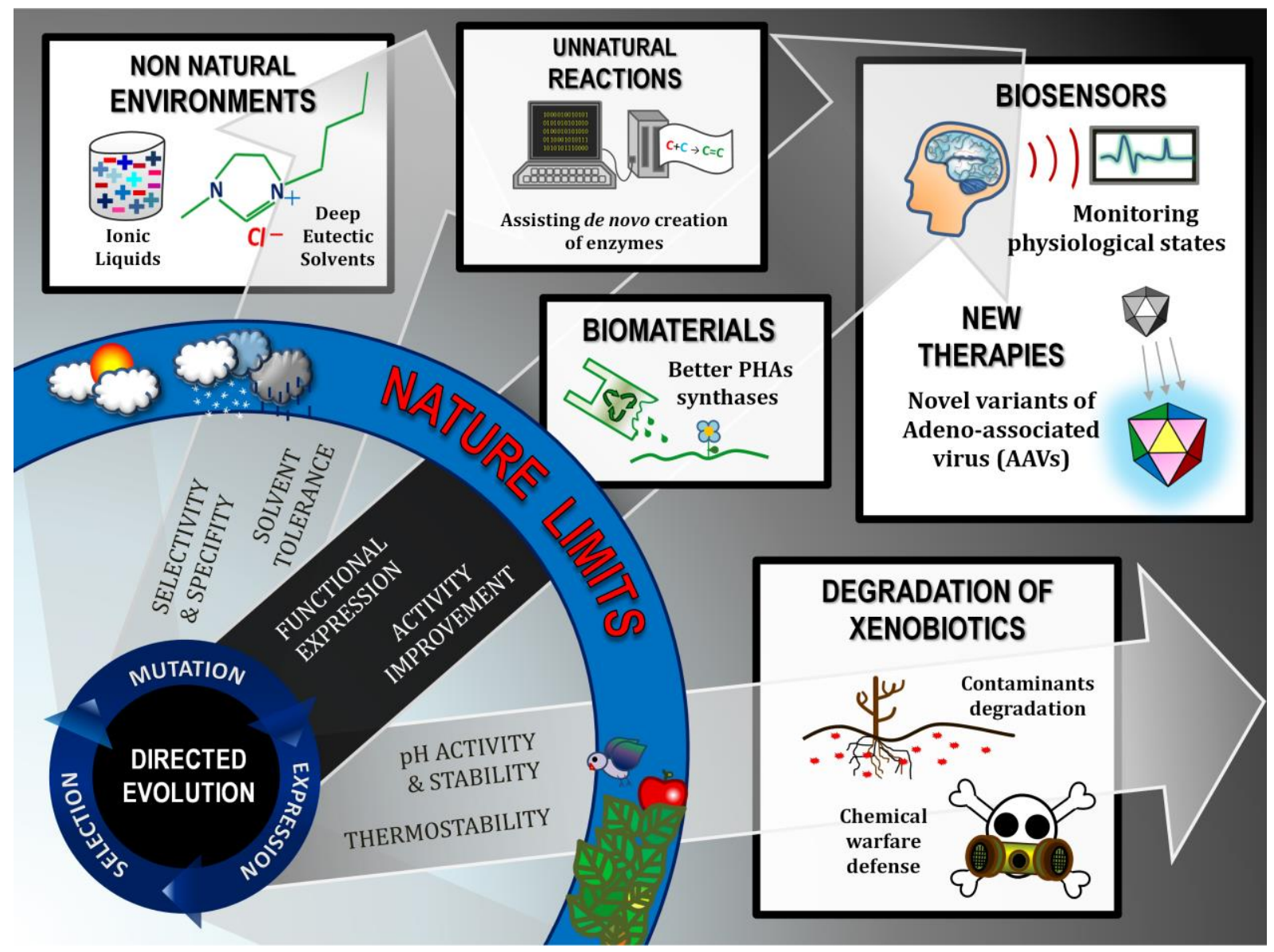

Fig. 1 
36
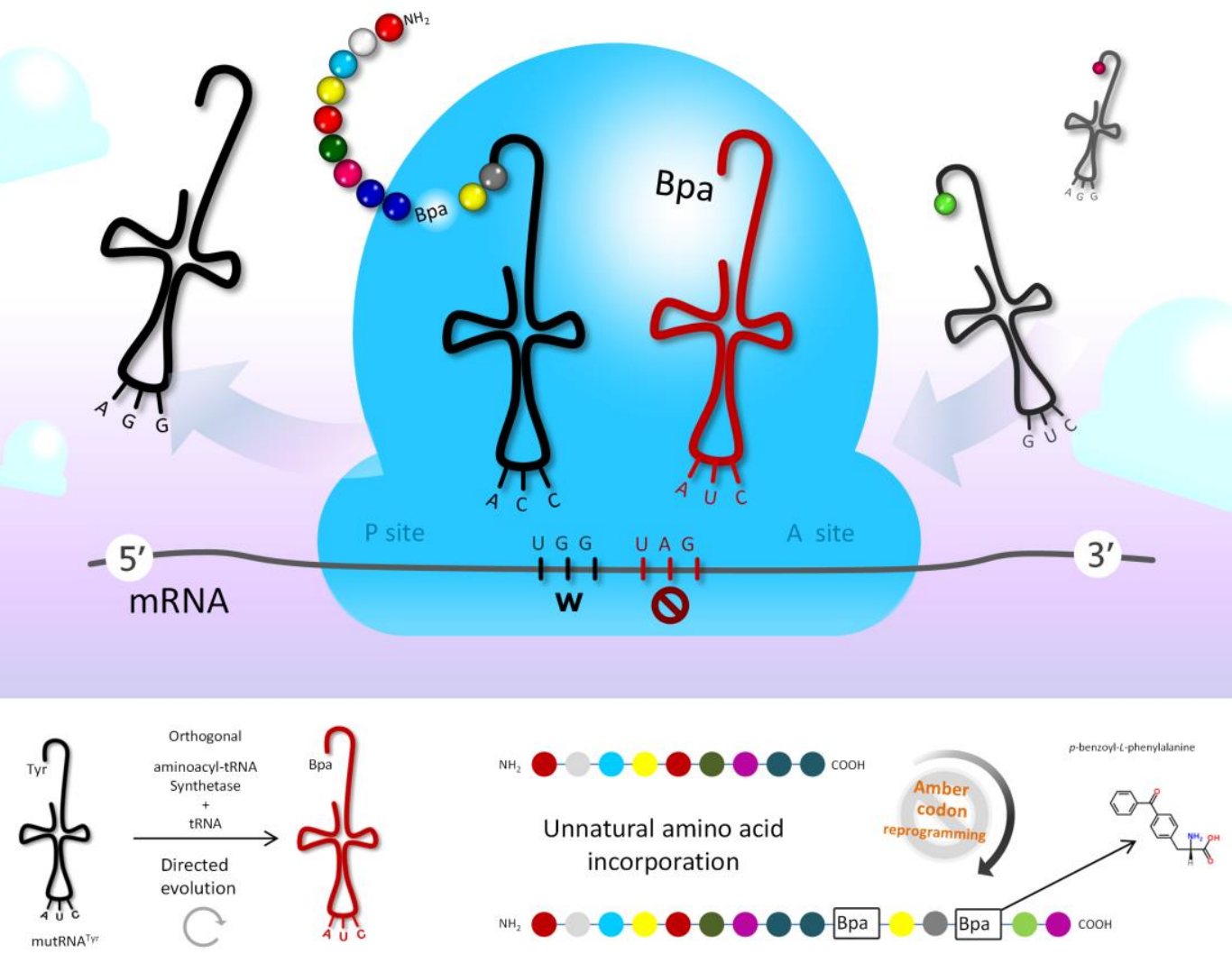

Fig. 2 


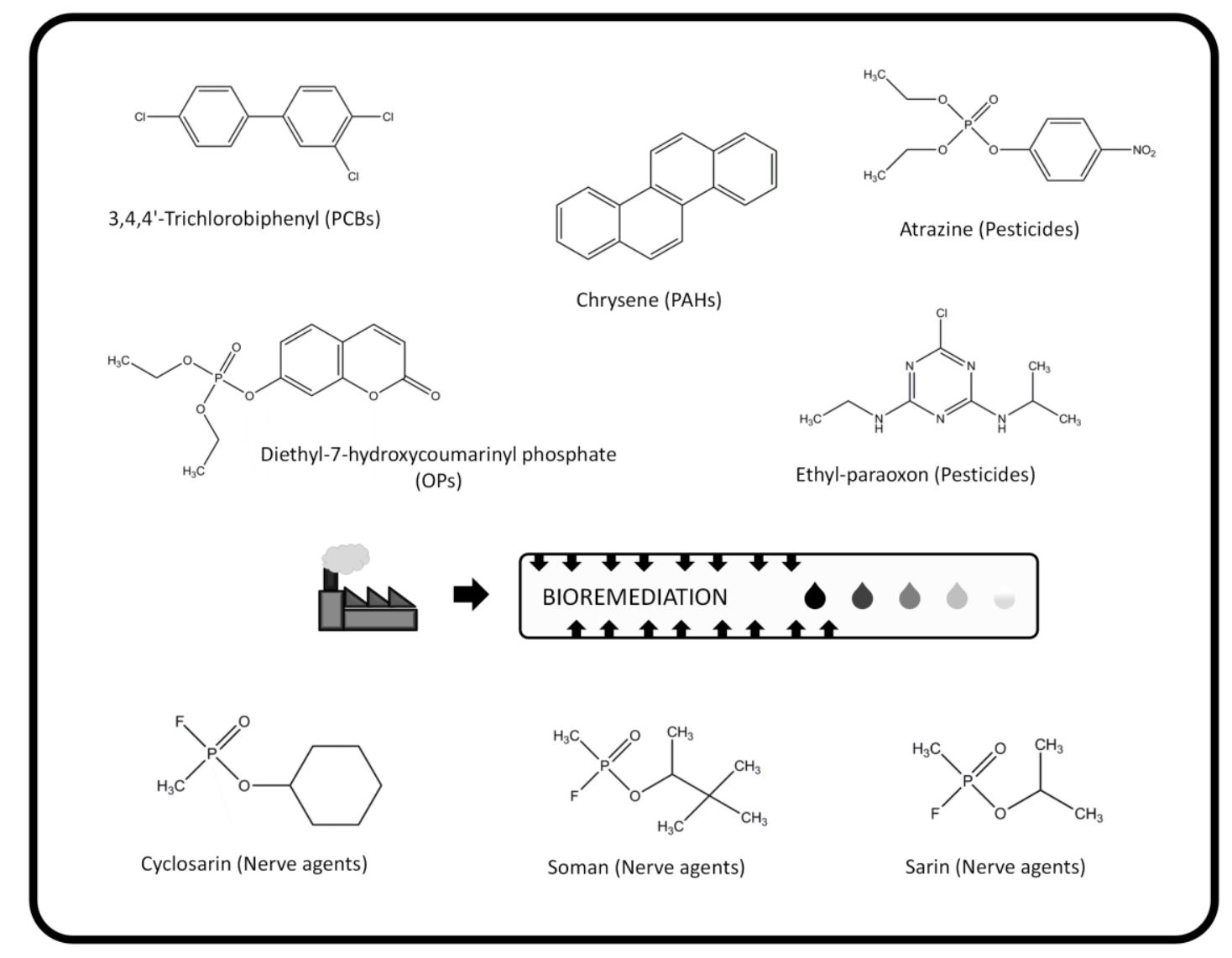

Fig. 3 
A

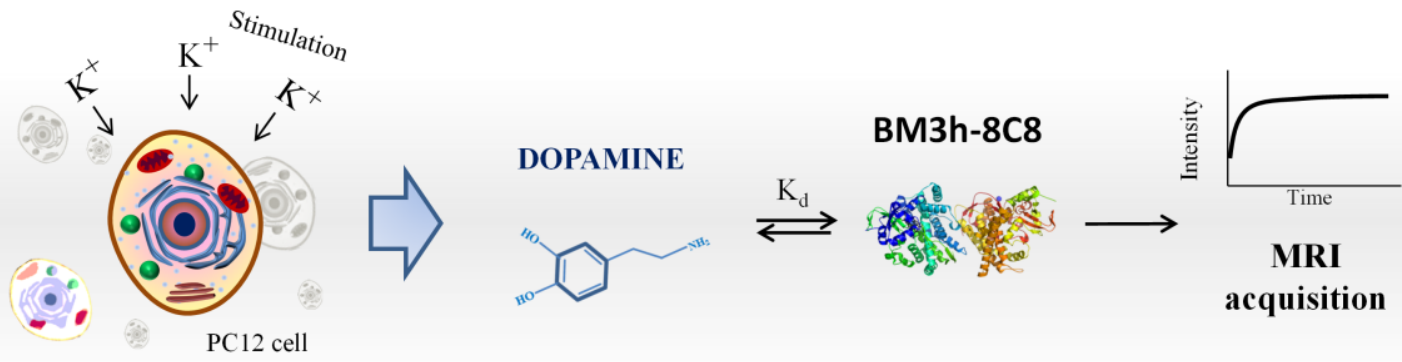

B
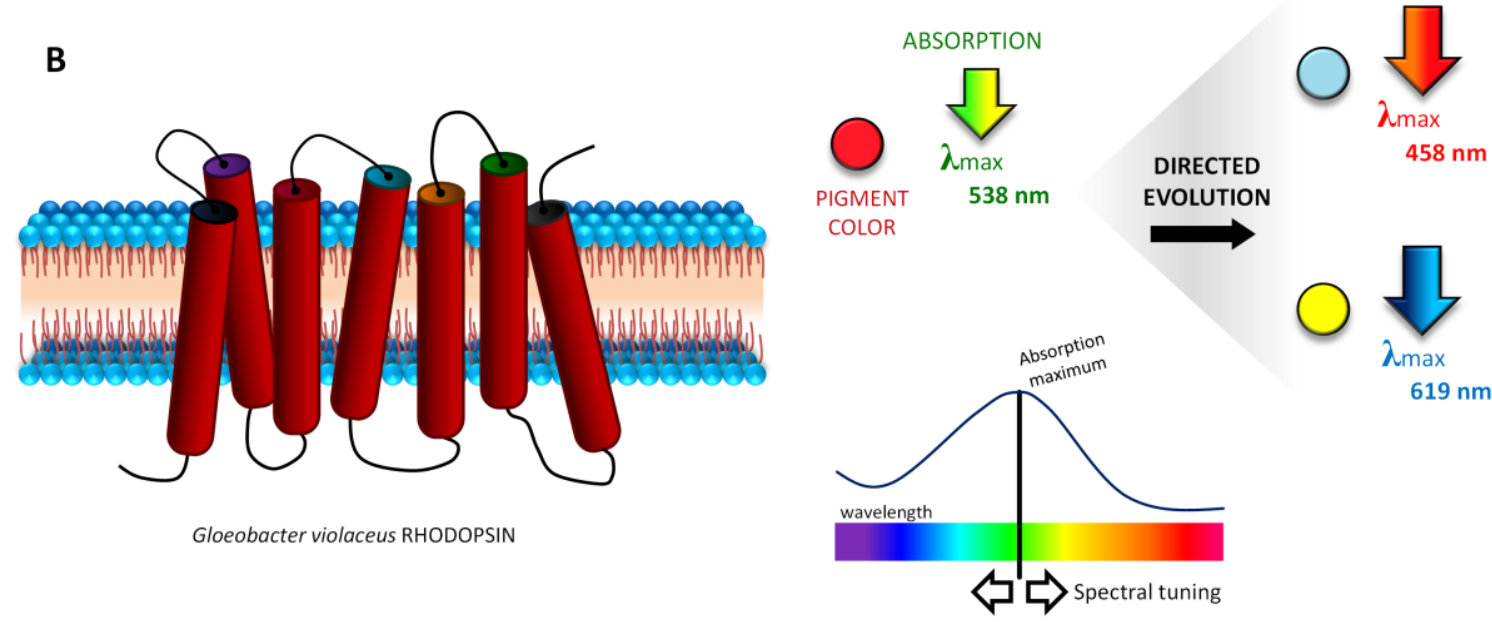

Fig. 4 